Provided for non-commercial research and education use. Not for reproduction, distribution or commercial use.

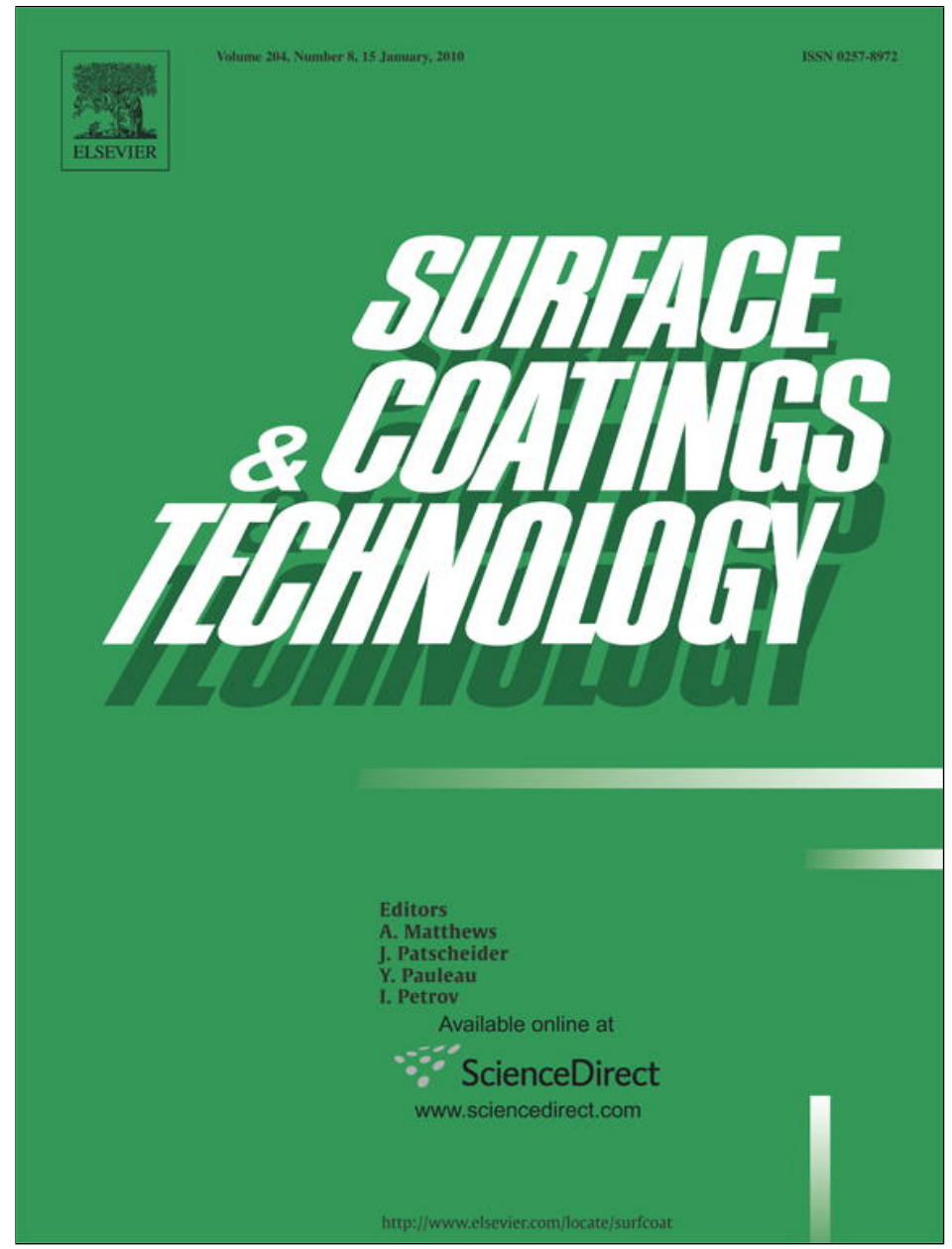

This article appeared in a journal published by Elsevier. The attached copy is furnished to the author for internal non-commercial research and education use, including for instruction at the authors institution and sharing with colleagues.

Other uses, including reproduction and distribution, or selling or licensing copies, or posting to personal, institutional or third party websites are prohibited.

In most cases authors are permitted to post their version of the article (e.g. in Word or Tex form) to their personal website or institutional repository. Authors requiring further information regarding Elsevier's archiving and manuscript policies are encouraged to visit:

http://www.elsevier.com/copyright 


\title{
Effect of the suspension composition on the microstructural properties of high velocity suspension flame sprayed (HVSFS) $\mathrm{Al}_{2} \mathrm{O}_{3}$ coatings
}

\author{
G. Bolelli ${ }^{\text {a,* }}$, V. Cannillo ${ }^{\text {a }}$, R. Gadow ${ }^{\mathrm{b}}$, A. Killinger ${ }^{\mathrm{b}}$, L. Lusvarghi ${ }^{\mathrm{a}}$, J. Rauch ${ }^{\mathrm{b}}$, M. Romagnoli $^{\mathrm{a}}$ \\ ${ }^{a}$ Department of Materials and Environmental Engineering, University of Modena and Reggio Emilia, Via Vignolese 905, 41100 Modena (MO), Italy \\ b Institute for Manufacturing Technologies of Ceramic Components and Composites (IMTCCC), Universität Stuttgart, Allmandring 7b, D-70569 Stuttgart, Germany
}

\section{A R T I C L E I N F O}

\section{Article history:}

Received 20 May 2009

Accepted in revised form 28 October 2009

Available online 4 November 2009

\section{PACS:}

81.15.Rs

81.05.Je

82.70.Kj

68.37.Hk

Keywords:

[C] High velocity suspension flame spraying

(HVSFS)

[D] Aluminium oxide

[B] Nanoindentation

[B] Roughness

[B] Scanning electron microscopy

\begin{abstract}
A B S T R A C T
Seven different $\mathrm{Al}_{2} \mathrm{O}_{3}$-based suspensions were prepared by dispersing two nano-sized $\mathrm{Al}_{2} \mathrm{O}_{3}$ powders (having analogous size distribution and chemical composition but different surface chemistry), one micronsized powder and their mixtures in a water + isopropanol solution. High velocity suspension flame sprayed (HVSFS) coatings were deposited using these suspensions as feedstock and adopting two different sets of spray parameters.

The characteristics of the suspension, particularly its agglomeration behaviour, have a significant influence on the coating deposition mechanism and, hence, on its properties (microstructure, hardness, elastic modulus). Dense and very smooth ( $\mathrm{Ra} \sim 1.3 \mu \mathrm{m}$ ) coatings, consisting of well-flattened lamellae having a homogeneous size distribution, are obtained when micron-sized $(\sim 1-2 \mu \mathrm{m})$ powders with low tendency to agglomeration are employed. Spray parameters favouring the break-up of the few agglomerates present in the suspension enhance the deposition efficiency (up to $>50 \%$ ), as no particle or agglomerate larger than $\sim 2.5 \mu \mathrm{m}$ can be fully melted. Nano-sized powders, by contrast, generally form stronger agglomerates, which cannot be significantly disrupted by adjusting the spray parameters. If the chosen nanopowder forms small agglomerates (up to a few microns), the deposition efficiency is satisfactory and the coating porosity is limited, although the lamellae generally have a wider size distribution, so that roughness is somewhat higher. If the nanopowder forms large agglomerates (on account of its surface chemistry), poor deposition efficiencies and porous layers are obtained.

Although suspensions containing the pure micron-sized powder produce the densest coatings, the highest deposition efficiency $(\sim 70 \%)$ is obtained by suitable mixtures of micron- and nano-sized powders, on account of synergistic effects.
\end{abstract}

(c) 2009 Elsevier B.V. All rights reserved.

\section{Introduction}

There has recently been a considerable scientific interest in thermal spray coatings manufactured from suspension feedstock instead of conventional dry powders [1-6]. The use of liquid suspensions enables very fine powder particles (micron-sized or nano-sized) to be delivered into the gas jet, overcoming the flowability troubles which would hinder their use in dry form. When the suspension is injected into a thermal spray gas jet, a series of interactions occur, involving: fragmentation of the suspension stream or suspension drops into small droplets; evaporation of the liquid phase from these droplets and subsequent release of individual micron- or nano-sized powder particles and/or of micrometric agglomerates; possible secondary disruption of the agglomerates; heating of the particles and agglomerates [7-11]. In all cases, these

\footnotetext{
* Corresponding author. Tel.: +39059 2056281; fax: +39059 2056243.

E-mail address: giovanni.bolelli@unimore.it (G. Bolelli).
}

particles or agglomerates are much smaller than a conventional dry powder feedstock for plasma- or high velocity oxygen-fuel- (HVOF) spraying, so that a smaller lamella size is always achieved $[10,1]$.

Very different results can also be obtained depending on the employed torch (single-cathode plasma torch with radial powder feeding, three-cathode and three-anode plasma torch with axial feeding, HVOF torch with axial injection, etc.), on the suspension formulation (powder size, solid content, type of solvent, additives, etc.), on the injection strategy and on the torch parameters [10,12-18]. Coatings may therefore be built up by partly unmolten agglomerates, where most of the original particles are preserved in an almost unaltered condition: this is particularly useful when processing heatsensitive functional materials, whose chemical composition and structure should not be altered; examples are perovskite layers for SOFCs cathodes [2], biocompatible hydroxyapatite layers [19] and photocatalytically-active $\mathrm{TiO}_{2}$ coatings with high anatase content $[3,4,20,21]$. Alternatively, individual particles and/or small agglomerates can be completely melted during spraying, so that the coating consists of well-flattened and densely-packed fine lamellae. Because of the small 
lamella size, thin $(\leq 50 \mu \mathrm{m})$ and dense layers can be manufactured $[5,1,15,22]$; indeed, a sufficiently large number of those lamellae can be superimposed in a thin layer: this would not be possible with thicker, conventionally-sprayed lamellae. Moreover, very small lamellae also imply very small pores and defects and low as-deposited roughness [5]. All of these characteristics are highly desirable for wear-resistant layers, dielectrics or SOFC electrolytes $[1,21,23]$.

Most of the papers cited above are focused on suspension plasma spraying, whereas fewer studies have examined suspension spraying using HVOF torches $[5,6,15-17,21,23]$. This latter process, however, seems to be particularly suitable for the production of dense layers (wear-resistant coatings, dielectrics, electrolytes for SOFCs, etc.). One of the most promising HVOF-suspension spraying techniques is the High Velocity Suspension Flame Spraying (HVSFS) process $[5,15,21,23]$, which employs a modified gas-fuelled HVOF torch in order to spray an axially-injected liquid feedstock.

Only few papers have systematically examined the effects of the processing parameters on the properties of suspension plasmasprayed coatings [12,13,16-18]. More specifically, the relations between the characteristics of the powder employed for suspension preparation (size, surface chemistry, etc.) and the final coating properties has not been frequently investigated [18]. No such report exists for HVSFS-deposited coatings.

The present research therefore aims to assess how the properties of HVSFS-deposited coatings are affected by the nature of the powder contained in the suspension and by the torch parameters. $\mathrm{Al}_{2} \mathrm{O}_{3}$ was selected as the coating material, on account of its widespread use in the thermal spray industry. It is relatively cheap and possesses high hardness and chemical stability, so that it is suitable for wear-resistant applications (even in corrosive environments and/or at high temperature), for electrical insulation, etc. [24]. Three different $\mathrm{Al}_{2} \mathrm{O}_{3}$ fine powders, commercially available from different suppliers, were employed: they differ either for the average particle size or for their acid/basic nature (determined by the surface pre-treatment of the powder). Seven different suspensions were employed in the spraying experiments: 3 suspensions contained each individual $\mathrm{Al}_{2} \mathrm{O}_{3}$ powder, 3 were produced using $50 \% / 50 \%$ mixtures of two of the powders and one consisted of a $1 / 3-1 / 3-1 / 3$ mixture of the three powders. The liquid phase composition, overall solid content and $\mathrm{pH}$ of the suspensions were kept constant. For each suspension, two different sets of spraying parameters were employed, so that 14 different coatings were produced and characterised.

\section{Experimental}

\subsection{Suspension preparation and coating deposition}

Three commercially-available $\mathrm{Al}_{2} \mathrm{O}_{3}$ powders were employed in the present experiments: two nano-sized powders, supplied by Taimei Chemicals Co. Ltd., Tokyo, Japan (hereinafter labelled as TAI), and by Nanostructured and Amorphous Materials Inc., Houston, Texas, USA (hereinafter labelled as NA), and a micron-sized one (CT-800 supplied by Mineral S.r.l., Formigine (MO), Italy; hereinafter referred to as CT).

Three suspensions were produced using the three individual powders (these suspensions will be hereinafter labelled as the corresponding powder, i.e. TAI, NA or CT, respectively). Three suspensions were produced using $1 / 2+1 / 2$ mixtures of two powders (hereinafter labelled as NA + TAI, CT $+\mathrm{NA}, \mathrm{CT}+\mathrm{TAI}$, respectively) and one suspension was produced using a $1 / 3+1 / 3+1 / 3$ mixture of the three powders (hereinafter labelled as $\mathrm{CT}+\mathrm{NA}+\mathrm{TAI}$ ). In all cases, $1 \mathrm{~kg}$ of suspension containing $20 \mathrm{wt} . \%$ of solid phase and $80 \mathrm{wt} . \%$ of a solution consisting of $40 \mathrm{wt} . \%$ isopropanol and $60 \mathrm{wt} . \%$ distilled water was prepared. The composition of the liquid phase, particularly the ratio between water and the organic solvent (isopropanol), is an important parameter for controlling the flame temperature in the
HVSFS process; indeed, water absorbs energy from the flame as it is vaporised and heated, whereas the organic solvent (isopropanol) contributes to the heat generation process by burning after vaporisation [5]. The $40 \mathrm{wt} . \% / 60 \mathrm{wt} . \%$ isopropanol/water ratio was chosen based on previous experience and preliminary experiments.

The suspensions were mechanically stirred for $1 \mathrm{~h}$ before the spray runs; during stirring, their $\mathrm{pH}$ was monitored with a $\mathrm{pH}$-meter and adjusted to $\sim 3.5$ by $\mathrm{HNO}_{3}$ addition. As the $\mathrm{pH}$ value critically affects the rheological behaviour of an $\mathrm{Al}_{2} \mathrm{O}_{3}$-based suspension $[25,26]$, adjustment of the $\mathrm{pH}$ guaranteed that the differences between the resulting coatings only depend on the characteristics of the solid phase (particle size and surface chemistry). The value of 3.5 was selected based on literature studies reporting aqueous $\mathrm{Al}_{2} \mathrm{O}_{3}$ suspensions to reach a highly positive Z-potential and, consequently, a good de-flocculation state [25].

As described in [21], in the HVSFS process, a suitable feeding system takes the suspension from a storage vessel (where it is mechanically stirred along the whole process duration) and delivers a continuous stream, at a controlled flow rate, to a modified HVOF torch (model: G-Gun, GTV GmbH, Luchenback, Germany). In this torch, the conventional dry powder injector is replaced by a conical suspension injector, ending with a $1 \mathrm{~mm}$ diameter. The torch is equipped with a specially-designed $135 \mathrm{~mm}$-long expansion nozzle featuring a $22 \mathrm{~mm}$-long conical combustion chamber.

For each suspension, two different sets of deposition parameters were employed (Table 1), labelled as "1" and "2", respectively. Fourteen coatings were thus produced: each coating is labelled according to the employed suspension and to the parameter set, i.e. CT-1, CT-2, NA-1, NA-2, etc.

The substrates were $(50 \times 50 \times 0.5) \mathrm{mm}^{3}$ plates of AISI 440 stainless steel, degreased using acetone and grit-blasted on both sides with $120 \mu \mathrm{m}$ angular white alumina grits, using a manual blasting gun operated at 5 bar pressure. The roughness of the blasted substrate surface was Ra $\sim 4 \mu \mathrm{m}$. The substrates were not preheated before spraying.

The surface temperature was monitored using an IR thermocamera during the deposition process. The samples were weighed before and after spraying, in order to determine the coating weight and compute the deposition efficiency.

\subsection{Characterisation of powders and suspensions}

The micron-sized CT powder was observed by scanning electron microscopy (SEM: XL30, FEI, Eindhoven, The Netherlands), whereas the nano-sized TAI and NA powders were examined by transmission electron microscopy (TEM: JEM 2010, JEOL, Tokyo, Japan). Their particle size distributions were assessed by image analysis ( $\mathrm{NIH}$ Image $1.37 \mathrm{v}$ ) on SEM and TEM micrographs having a resolution of $0.045 \mu \mathrm{m} /$ pixel and $1.23 \mathrm{~nm} /$ pixel, respectively. For each powder, at least 5 micrographs were acquired and at least 300 particles were measured.

Table 1

HVSFS deposition parameters.

\begin{tabular}{lll}
\hline Parameters & Settings & \\
\cline { 2 - 3 } & $\# 1$ & $\# 2$ \\
\hline Fuel (propane) flow rate $(\mathrm{Sl} / \mathrm{min})$ & 55 & 60 \\
$\mathrm{O}_{2}$ flow rate $(\mathrm{Sl} / \mathrm{min})$ & 325 & 350 \\
Suspension flow rate $(\mathrm{g} / \mathrm{min})$ & 66.7 & \\
Substrate cooling system & Compressed air jets & \\
Gun traverse speed $(\mathrm{mm} / \mathrm{s})$ & 600 & \\
Interpass spacing $(\mathrm{mm})$ & 1 & 400 \\
Stand-off distance $(\mathrm{mm})$ & 130 & \\
Number of cycles & 2 & \\
Maximum deposition temperature $\left({ }^{\circ} \mathrm{C}\right)$ & 300 & \\
\hline
\end{tabular}


The chemical composition of the powders was analysed by X-ray Fluorescence (XRF: ARL Advant'X, Thermo Electron Corp., Waltham, Maine, USA) and their phase composition was assessed by X-ray diffraction (XRD: X'Pert Pro, PANAlytical, Almelo The Netherlands), using $\mathrm{Ni}$-filtered $\mathrm{Cu}-\mathrm{K}_{\alpha}$ radiation from an $\mathrm{X}$-ray emission tube operated at $40 \mathrm{~mA}, 40 \mathrm{kV}$; the patterns were acquired in the $23^{\circ}<2 \theta<82^{\circ}$ range at a $0.017^{\circ}$ scanning step. The ratio between $\alpha-$ $\mathrm{Al}_{2} \mathrm{O}_{3}$ and $\gamma-\mathrm{Al}_{2} \mathrm{O}_{3}$ was determined by the intensities of the (311) and (400) peak, respectively, according to the formula (1), already employed in $[23,27]$ :

$R_{\alpha / \gamma}=\frac{1}{1+1.08 \frac{I_{\frac{(400)}{I_{(311)}}}^{I}}{1+x}}$

where:

$I_{(311)} \quad$ integral intensity of the $\alpha-\mathrm{Al}_{2} \mathrm{O}_{3}$ (311) peak;

$I_{(400)} \quad$ integral intensity of the $\gamma-\mathrm{Al}_{2} \mathrm{O}_{3}$ (400) peak;

1.08 correction coefficient, accounting for structure factors, peak multiplicities and unit cell volumes.

The integral intensities were assessed by non-linear least squares pattern fitting, performed using the dedicated MarqX software [28].

The average crystal grain size was computed by the Scherrer Eq. (2) [29] using the same fitted patterns:

$D_{\mathrm{hkl}}=\frac{0.96 \cdot \lambda}{\beta_{\mathrm{hkl}} \cos \theta}$

where

$\lambda \quad$ radiation wavelength $(1.54060 \AA)$;

$\beta_{\mathrm{hkl}} \quad$ full width at half-maximum height of the selected diffraction peak;

$\theta \quad$ diffraction angle;

$D_{\mathrm{hkl}} \quad$ average crystal size measured using the (hkl) peak.

The size distributions of the agglomerates formed in the 7 suspensions were measured by a laser diffraction particle size analyser (Mastersizer 2000, Malvern Instruments, Malvern, UK). One set of measurements was done with no ultrasonication, in order to evaluate the size of the agglomerates which were spontaneously formed when the suspension was handled in a similar manner as during the HVSFS process; a second set of measurements was performed after 2 min ultrasonication, in order to evaluate the strength of the agglomerates.

The viscosity of the 7 suspensions was measured using a rotating viscosimeter (UDS 200, Universal Dynamics Spectrometer, Physica Messtechnik GmbH, Stuttgart, Germany) with cylindrical geometry (cylindrical probe diameter $45 \mathrm{~mm}$, in accordance to DIN Z2 system). The shear rate was varied between $0.1 \mathrm{~s}^{-1}$ and $500 \mathrm{~s}^{-1}$ in 200 steps, each data point was acquired with a measurement duration of $3 \mathrm{~s}$.

\subsection{Characterisation of HVSFS-deposited coatings}

The polished cross-sections (cold-mounted in resin, ground and eventually polished with $0.5 \mu \mathrm{m}$ diamond slurry) and fractured sections (obtained by breaking thin bar samples in liquid nitrogen) of the as-deposited coatings were examined by SEM. Their top surface was observed by environmental scanning electron microscopy (ESEM: Quanta 200, FEI, Eindhoven, The Netherlands) under low vacuum conditions ( 1 mbar pressure).

The porosity was measured by image analysis (ImageJ) on $1000 \times$ cross-sectional SEM micrographs (resolution $0.18 \mu \mathrm{m} /$ pixel) acquired in backscattered electron mode, according to the procedure described in [30]. The thickness of the coatings was also measured by image analysis on low-magnification micrographs. The surface roughness was measured by a contact profilometer (Perthometer PGK, Mahr, Göttingen, Germany). Four measurements were performed on each coating.

The phase composition of the coatings was assessed by XRD, operating in the same conditions described above. The $\alpha / \gamma$ phase ratio was determined using the Eq. (1), as for the feedstock powder.

Depth-sensing Berkovich nanoindentation (Nanoindenter, CSM Instruments, Peseux, Switzerland) was performed on the polished cross-sectional samples, using indentation loads of $50 \mathrm{mN}$ (loading/ unloading rate $40 \mathrm{mN} / \mathrm{min}$, holding time: $10 \mathrm{~s}$ ), $300 \mathrm{mN}$ (loading/ unloading rate $240 \mathrm{mN} / \mathrm{min}$, holding time: $10 \mathrm{~s}$ ) and $500 \mathrm{mN}$ (loading/unloading rate $400 \mathrm{mN} / \mathrm{min}$, holding time: $10 \mathrm{~s}$ ); 15 indentations were performed for each load value. The hardness and the elastic modulus were computed according to the Oliver-Pharr procedure [31]: the Poisson's ratio was assumed to be 0.23 .

\section{Results}

\subsection{Characterisation of powders and suspensions}

As expected, the CT powder consists of micrometre-sized particles (Fig. 1A) with $d_{10}=0.5 \mu \mathrm{m}, d_{50}=2.1 \mu \mathrm{m}, d_{90}=4.1 \mu \mathrm{m}$, as determined by image analysis on SEM micrographs (the particle size distribution curves are shown in Fig. 2A and values are summarised in Table 2); notably, several particles display a platelet-like morphology (Fig. 2A).

The nano-sized NA and TAI powders are obviously much finer (Fig. 1B,C) and, most remarkably, they both consist of rounded particles with very similar size distributions (Fig. 2B,C). These particles seem to be strongly cohesive; indeed, they formed agglomerates on the TEM sample holder, so that, when analysing the micrographs, the individual particles must be discerned inside the larger agglomerates. The $d_{10}, d_{50}$, $d_{90}$ values of the NA and TAI powders, assessed by image analysis on TEM micrographs, are $46.8 \mathrm{~nm}, 76.9 \mathrm{~nm}, 122.6 \mathrm{~nm}$ and $49.9 \mathrm{~nm}$, $79.7 \mathrm{~nm}, 121.9 \mathrm{~nm}$, respectively (Fig. 2B,C and Table 2).

$\mathrm{X}$-ray diffraction patterns reveal that all of the three powders consist of pure $\alpha-\mathrm{Al}_{2} \mathrm{O}_{3}$ phase (rhombohedral structure, JCPDS 10-173). According to the Scherrer analysis, the average crystalline grain size of the NA and TAI powders are $76 \mathrm{~nm}$ and $75 \mathrm{~nm}$, respectively. These values are well matched to the image analysis results: they indicate that the particles consist of single crystals and they corroborate to the substantial similarity between the particle size distributions of these two powders. The average crystalline grain size of the CT powder is $126 \mathrm{~nm}$, which indicates that, in this case, many particles are polycrystalline.

The XRF chemical analysis also reveals that all of the powders possess a remarkable chemical purity (>99.5\%): no impurity element appears in substantial amounts.

Most remarkably, all of the previous analyses indicate a substantial similarity between the NA and TAI powders: they both consist of pure $\alpha-\mathrm{Al}_{2} \mathrm{O}_{3}$ particles having analogous size distribution and comparable purity.

Notwithstanding this similarity, the NA and TAI powders were subjected to different chemical pre-treatments by the two distinct manufacturers, so that, when producing the water + isopropanol suspensions, the former powder exhibits basic hydrolysis and spontaneously generates a $\mathrm{pH}$ of 9.8 , whereas the latter displays acid behaviour and brings the $\mathrm{pH}$ of the suspension down to 5.5. The CT powder produces a basic $\mathrm{pH}$ value of 8.0.

The following results were found when using the laser diffraction technique for measuring the size distribution of the agglomerates in the suspensions, whose $\mathrm{pH}$ was always adjusted to 3.5 as specified in the Experimental section (Fig. 3B,C; Table 2):

- The NA suspension contains much smaller agglomerates than the TAI one, the difference being as large as one order of magnitude. Ultrasonication can partly disrupt the very large agglomerates found 

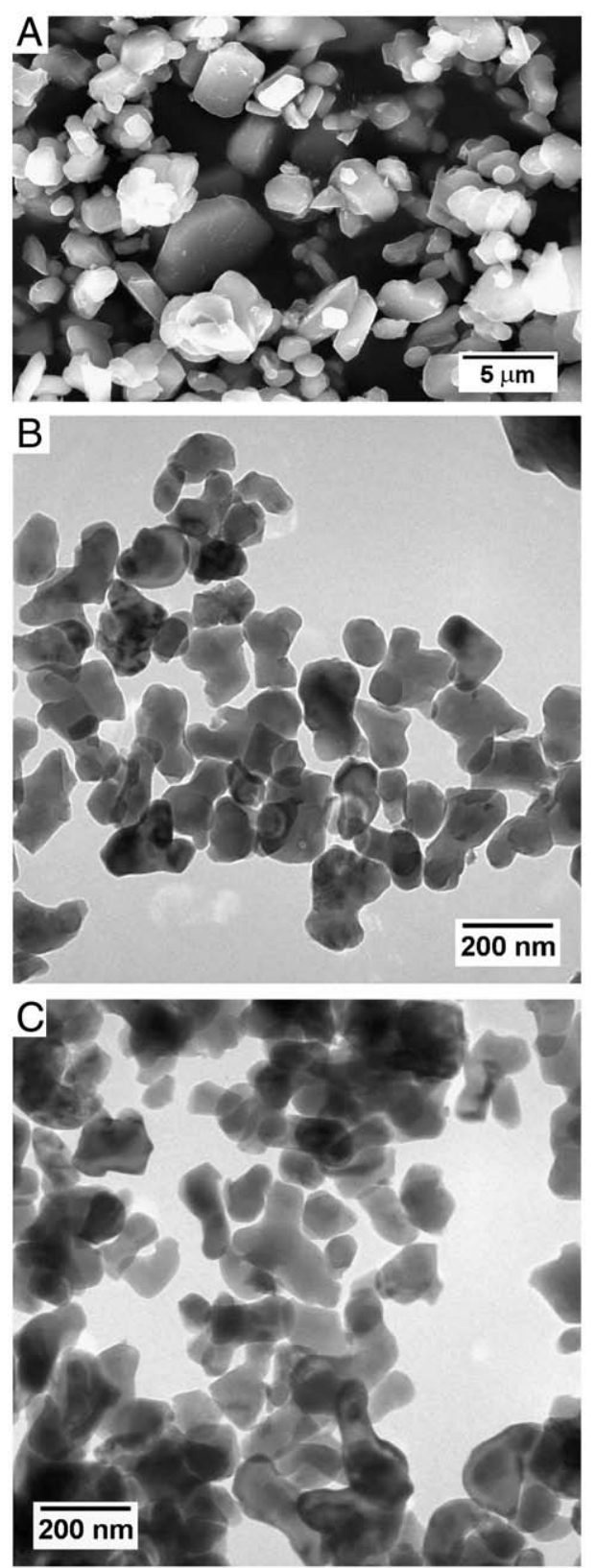

Fig. 1. SEM micrograph of the CT powder (A) and TEM micrographs of the NA (B) and TAI (C) powders.

in the TAI suspension, but the difference between the two still remains very significant (Table 2 ).

- The CT suspension exhibits a multimodal size distribution. Specifically, the distributive curve possesses two main peaks (Fig. 3A): the first one has a maximum located at about $2 \mu \mathrm{m}$ and it definitely resembles the size distribution of the individual micrometric particles (compare to Fig. 2A), so that it presumably consists of non-agglomerated primary particles. The second peak has its maximum at about $70 \mu \mathrm{m}$ : it clearly consists of some large agglomerates. This means the CT powder has a much lower tendency towards aggregation than the NA and TAI ones, which are entirely agglomerated (as clearly seen in Table 2 as well). Additionally, complete disruption of the agglomerates in the CT suspension occurs after ultrasonication: the size distribution measured on the CT suspension by laser diffraction after 2 min ultrasonication becomes nearly coincident with the primary particle size distribution, previously measured by image analysis on SEM micrographs (Fig. $3 \mathrm{H}$ and Table 2). This result indicates that these
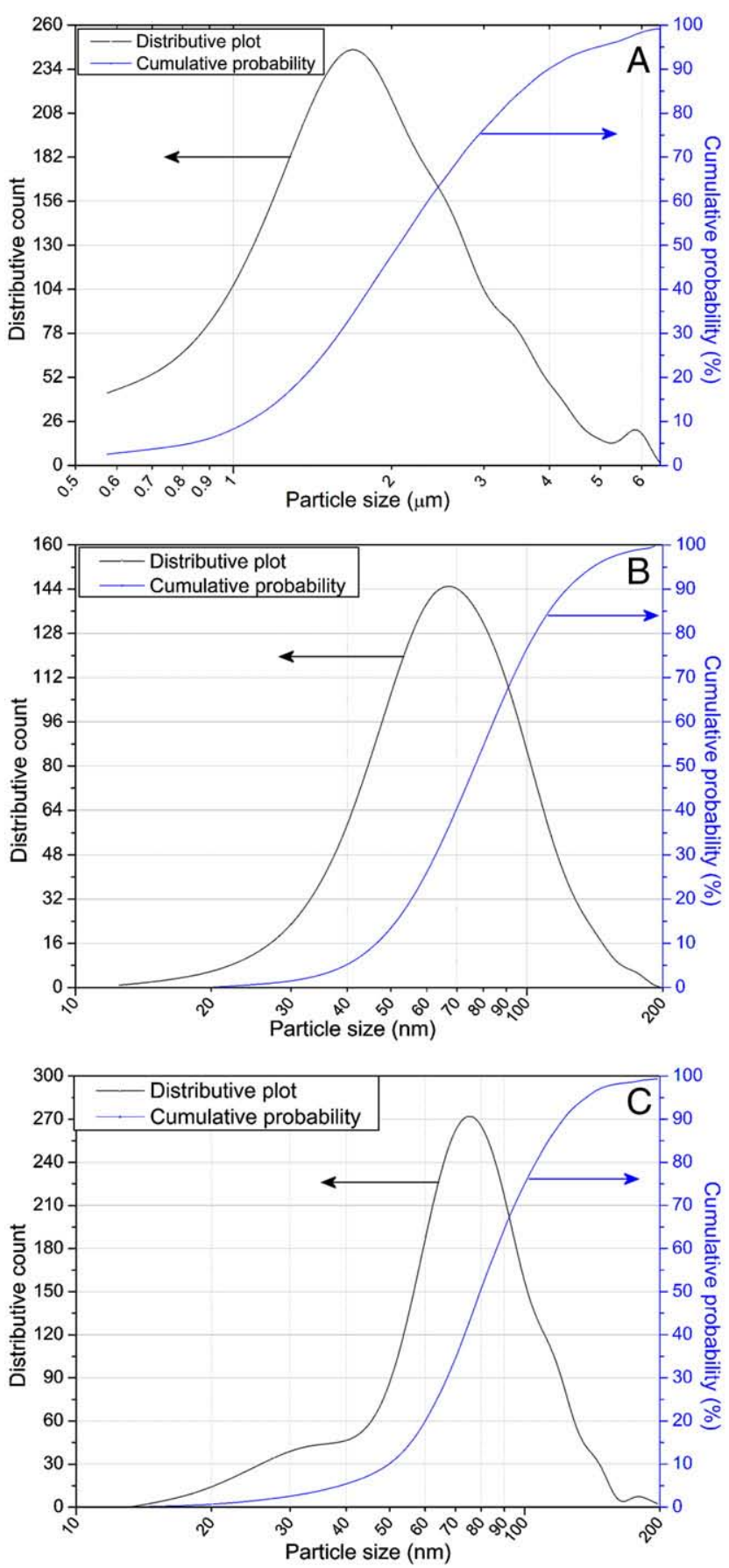

Fig. 2. Distributive and cumulative curves of the CT (A), NA (B) and TAI (C) powders.

agglomerates are definitely weaker than those formed in the NA and TAI suspensions, which cannot be entirely disrupted by the same ultrasonication treatment.

- The suspensions produced by the mixtures of two or three powders always display a multimodal particle size distribution. Specifically, the distributive curve of the CT + NA suspension exhibits two main peaks at $1 \mu \mathrm{m}$ and $\sim 4.5 \mu \mathrm{m}$, respectively (Fig. 3D).

- The addition of the TAI powder ( CT + TAI and CT + NA + TAI suspensions, Fig. 3E,F) shifts the second maximum towards larger values, consistently with the remarkable cohesiveness of the TAI powder. The NA + TAI suspension also shows a multimodal particle size distribution with a secondary maximum at large equivalent diameter values (Fig. 3G), because of the effect of the TAI powder. In all cases, ultrasonication reduces the size of the agglomerates but does 
Table 2

$D_{10}, D_{50}$ and $D_{90}$ values of the various suspensions, measured by laser diffraction with and without ultrasonication.

\begin{tabular}{|c|c|c|c|c|c|c|}
\hline \multirow[t]{2}{*}{ Suspension label } & \multicolumn{3}{|c|}{ No ultrasonication } & \multicolumn{3}{|c|}{2 min ultrasonication } \\
\hline & $\begin{array}{l}D_{10} \\
(\mu \mathrm{m})\end{array}$ & $\begin{array}{l}D_{50} \\
(\mu \mathrm{m})\end{array}$ & $\begin{array}{l}D_{90} \\
(\mu \mathrm{m})\end{array}$ & $\begin{array}{l}D_{10} \\
(\mu \mathrm{m})\end{array}$ & $\begin{array}{l}D_{50} \\
(\mu \mathrm{m})\end{array}$ & $\begin{array}{l}D_{90} \\
(\mu \mathrm{m})\end{array}$ \\
\hline CT & 0.73 & 2.89 & 74.78 & 0.58 & 2.08 & 4.83 \\
\hline NA & 0.53 & 1.52 & 9.81 & 0.51 & 1.44 & 6.77 \\
\hline TAI & 0.61 & 18.29 & 51.96 & 0.30 & 5.65 & 14.89 \\
\hline $\mathrm{CT}+\mathrm{NA}$ & 0.60 & 2.76 & 20.19 & 0.57 & 2.47 & 9.66 \\
\hline $\mathrm{CT}+\mathrm{TAI}$ & 0.67 & 5.50 & 29.65 & 0.52 & 4.32 & 11.21 \\
\hline $\mathrm{CT}+\mathrm{NA}+\mathrm{TAI}$ & 0.56 & 3.01 & 18.59 & 0.52 & 2.49 & 9.79 \\
\hline $\mathrm{NA}+\mathrm{TAI}$ & 0.51 & 1.99 & 23.68 & 0.46 & 1.55 & 10.69 \\
\hline Dry powder label & \multicolumn{2}{|c|}{$\mathrm{D}_{10}(\mu \mathrm{m})$} & \multicolumn{2}{|c|}{$\mathrm{D}_{50}(\mu \mathrm{m})$} & \multicolumn{2}{|c|}{$\mathrm{D}_{90}(\mu \mathrm{m})$} \\
\hline CT powder (SEM micrographs) & \multicolumn{2}{|l|}{0.5} & \multicolumn{2}{|l|}{2.1} & \multicolumn{2}{|l|}{4.1} \\
\hline NA powder (TEM micrographs) & \multirow{2}{*}{\multicolumn{2}{|c|}{$46.8 * 10^{-3}$}} & \multicolumn{2}{|c|}{$76.9 * 10^{-3}$} & \multicolumn{2}{|c|}{$122.6 * 10^{-3}$} \\
\hline TAI powder (TEM micrographs) & & $49.9 * 10^{-3}$ & \multicolumn{2}{|c|}{$79.7 * 10^{-3}$} & \multicolumn{2}{|c|}{$121.9 * 10^{-3}$} \\
\hline
\end{tabular}

The $D_{10}, D_{50}$ and $D_{90}$ values of the dry powders, determined by image analysis on SEM and TEM micrographs, are also listed for comparison.

not disrupt them completely; moreover, the agglomerate size distribution still tends to become coarser whenever the TAI powder is present (Table 2).

In spite of the much different agglomeration behaviour, the rheometer measurements do not reveal any substantial difference between the various suspensions: all of the viscosity values lay between $4 \mathrm{mPas}$ and $10 \mathrm{mPas}$, and the suspension behaviour is almost Newtonian over the tested shear rate range. For instance, the comparison between the viscosity curves of the CT, NA and TAI suspensions is given in Fig. 4.

These viscosity values are very low: as a term of comparison, the viscosity of pure distilled water at $20^{\circ} \mathrm{C}$ is $1 \mathrm{mPas}$. This is most probably caused by the limited solid content of the suspensions (20 wt.\%). At such low viscosity values, the differences between the suspensions are so small, that they cannot be appreciated by the present measurement technique.

\subsection{Characterisation of HVSFS-deposited coatings}

\subsubsection{Structural and microstructural analysis}

Remarkable differences exist between the thickness and porosity values of the various coatings, as summarised in Table 3. Consistently, deposition efficiency values also show large variations. Of the coatings deposited using suspensions which contain only one powder type, the CT- 1 and CT-2 ones are definitely the densest, as SEM micrographs also show (Fig. 5), whereas the TAI-1 and TAI-2 coatings exhibit the highest porosity and largest average pore size. When suspensions consisting of nano-sized powders are employed, indeed, the polished cross-sections of the coatings always show some large, elongated defects. This is particularly true when the TAI powder is employed (Fig. 5E,F). These defects are obviously consistent with the increase in both the overall porosity and the average pore size. Moreover, the presence of these defects, scattered throughout the coating, increases the statistical dispersion of the porosity values: accordingly, the percent porosity values of the coatings deposited using suspensions which contained the TAI powder typically possess a larger standard deviation (Table 3 ).

The TAI- 1 and TAI- 2 coatings are also the thinnest; indeed, the TAI powder produces the lowest deposition efficiency. Quite interestingly, the CT suspension produces the highest deposition efficiency when using the parameter set \#2, but not with parameter set \#1 (Table 3); indeed, the deposition efficiency of the CT suspension is more deeply affected by variations in the spray parameters (from parameter set 1 to parameter set 2) than that of the NA and TAI suspensions.

More specifically, fractured section views highlight that:

- Both CT coatings mostly consist of quite well-flattened lamellae, whose diameter ranges from $\leq 1 \mu \mathrm{m}$ to $\sim 6 \mu \mathrm{m}$ (Fig. $6 \mathrm{~A}$ ): their good flattening is perfectly consistent with the low porosity and small pore size found in the CT coatings (Table 3). Most of these lamellae contain columnar grains of $\sim 100 \mathrm{~nm}$ width (Fig. 6B); additionally, in the middle of some of them, extremely small (nanometric) equiaxed grains appear (Fig. 6C, see circle). These lamellae probably experienced a particularly fast cooling rate, which makes the process of homogeneous nucleation of crystals inside the melt competitive with the heterogeneous nucleation from the lamellar boundary, normally taking place in most lamellae [27].

- Some embedded spherical particles, with a diameter of $\leq 500 \mathrm{~nm}$, also appear (Fig. 6D): their spherical shape clearly reveals that they were fully melted in the gas jet, but had started to re-solidify before impinging onto the substrate.

- Compared to the CT coatings, the lamellae in the NA ones are smaller and exhibit a broader size distribution (compare Figs. 7A and 6A). Most of the flattened lamellae are $2-3 \mu \mathrm{m}$ wide and various small rounded particles $(\sim 200-500 \mathrm{~nm}$ diameter) are present (more numerous than in the CT coating). Moreover, some nanoparticle agglomerates are embedded in the coating in a largely unmelted condition, resulting in localised highly-defective areas (Fig. 7B).

- The unmelted nanoparticle agglomerates are definitely more numerous in the TAI coatings (Fig. 8).

If the coatings obtained using powder mixtures are also considered (Table 3), it can immediately be noted that mixing the CT or NA powders with the TAI one tends to increase the porosity and the average pore size. The thickness and the deposition efficiency of the NA + TAI- 1 and NA + TAI-2 coatings are also lower than those of the pure NA- 1 and NA-2 coatings. The deposition efficiency of the CT + TAI suspension is higher than that of the pure CT suspension with spraying parameter set \#1, but lower with parameter set \#2.

The CT + NA- 1 and CT + NA-2 coatings are also more porous than the pure CT coatings, but they are significantly thicker, as well: a peculiar synergistic effect on the deposition efficiency seems to occur when the CT and NA powders are mixed.

In all cases, the thickness and deposition efficiency are not significantly affected by the selection of spraying parameters.

Fractured section views highlight that, on the top surface of the CT + NA + TAI coatings, lots of small rounded droplets (re-solidified small agglomerates) and of unmelted nanoparticles are present together with the larger and well-flattened splats produced by the micron-sized CT particles (Fig. 9); clusters of unmelted nanoparticles, quite similar to those found in the pure TAI coating and shown in Fig. 8, also appear along the cross-section.

In general, as the torch performed only two scanning cycles in front of the substrate, the thickness deposited per torch cycle is, in all cases, quite large (from $16.5 \mu \mathrm{m}$ to $>60 \mu \mathrm{m}$, depending on the powder type and on the parameter set), one order of magnitude greater than the values reported for suspension plasma-sprayed $\mathrm{Al}_{2} \mathrm{O}_{3}[12,13]$.

XRD patterns (Fig. 10) reveal that all coatings consist of $\alpha-\mathrm{Al}_{2} \mathrm{O}_{3}$, $\gamma-\mathrm{Al}_{2} \mathrm{O}_{3}$ and some glassy phase (whose presence is indicated by an amorphous hump), which is typical for thermally-sprayed alumina [23,32]. A Fe-b.c.c. (ferrite) peak also emerges, particularly from the thinnest coatings, because of the contribution from the substrate. Some differences exist between the amounts of the $\alpha-\mathrm{Al}_{2} \mathrm{O}_{3}$ and $\gamma$ $\mathrm{Al}_{2} \mathrm{O}_{3}$ phases in the various coatings, as listed in Table 3 . Specifically, the use of the TAI powder (pure or in mixtures) seems to increase the $\alpha-\mathrm{Al}_{2} \mathrm{O}_{3}$ content for a given set of deposition parameters (the $\mathrm{CT}+$ TAI- 2 coating being the only exception).

\subsubsection{Surface roughness and surface morphology}

The CT- 1 and CT-2 coatings are definitely the smoothest (Table 4). SEM micrographs (Fig. 11A,B) clearly indicate that the presence of a uniform distribution of well-flattened lamellae having similarly small size (in the 1-6 $\mu \mathrm{m}$ range, as also noted in Section 3.2.1) is the reason for this excellent as-deposited smoothness. 

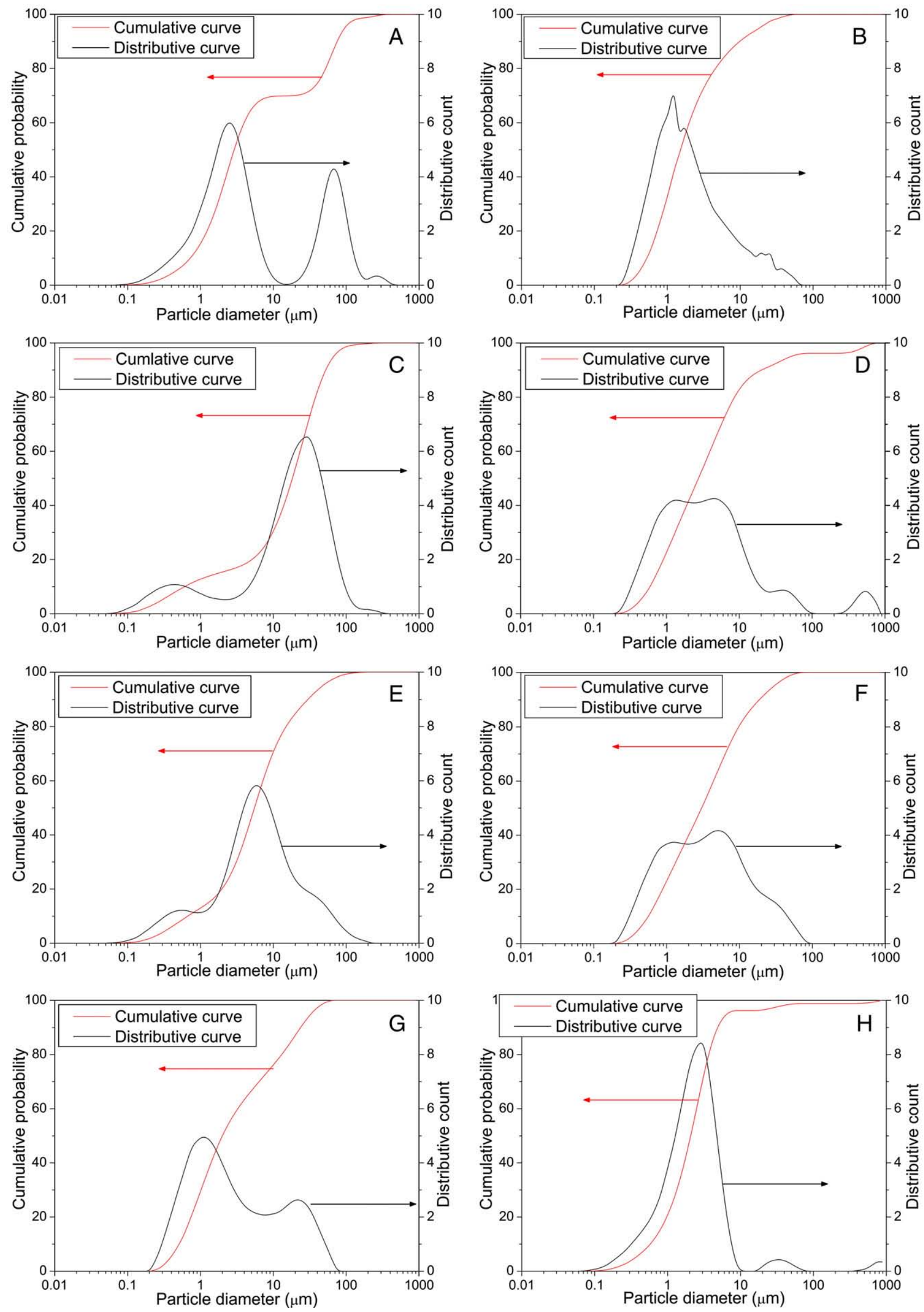


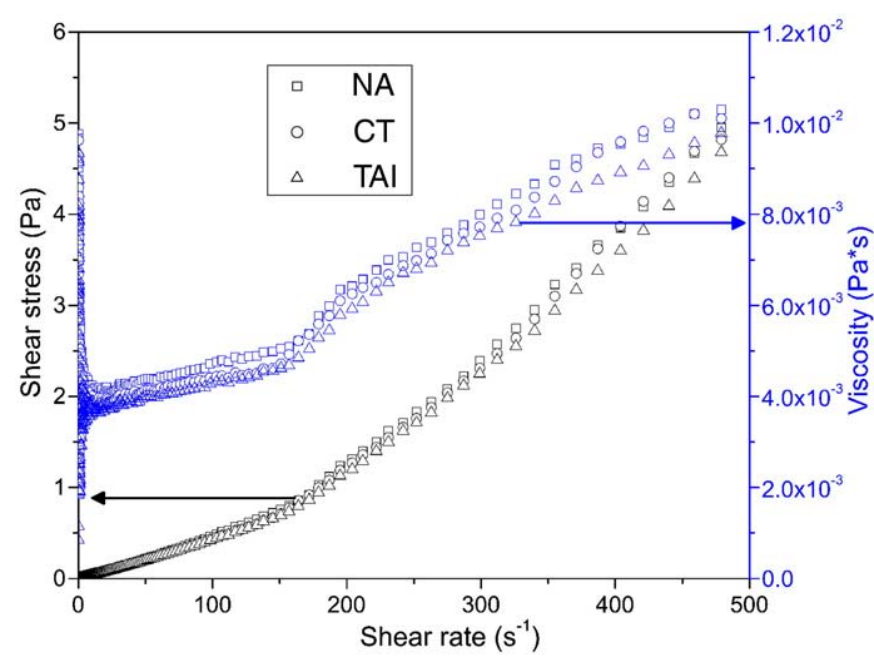

Fig. 4. Viscosity of the CT, NA and TAI suspensions and applied shear stress, as a function of the shear rate.

The NA and TAI coatings, as well as the coatings obtained by mixed-powder suspensions, are somewhat rougher; indeed, the uniformity of the surface morphology is reduced by the less homogeneous size distribution of the lamellae (Fig. 11C,D) and by the many small, rounded, non-flattened particles. Additionally, when the TAI powder is employed in the suspension (either pure or mixed with other powders), the previously-discussed partially unmelted agglomerates result in some very large surface defects ( $>50 \mu \mathrm{m}$ : one of them is highlighted by the circle in Fig. 11E and a detail of the unmelted nanoparticles is shown in Fig. 11F), randomly scattered throughout the coating's surface.

\subsubsection{Nanoindentation tests}

The hardness and elastic modulus values of the various coatings are consistent with their porosity and with the previous microstructural analysis. With very few exceptions, the CT- 1 and CT-2 coatings show higher hardness and elastic modulus than all other coatings, irrespective of the indentation load (Figs. 12 and 13); moreover, when the CT powder is mixed with the NA or the TAI ones, the mechanical properties of the resulting coatings are decreased, in accordance to the higher defectiveness.

In most cases, for a given coating, the hardness and elastic modulus values measured under an indentation load of $50 \mathrm{mN}$ are significantly larger than those measured at $300 \mathrm{mN}$ and $500 \mathrm{mN}$; the latter values, by contrast, are generally quite close to one another.

\section{Discussion}

The above listing of SEM and XRD results clearly points out to the presence of several peculiar phenomena, which need to be explained on the basis of the lamella formation mechanisms. These latter should therefore be examined and related to the suspension characteristics.

Generally speaking, the processes taking place once the suspension stream is injected into the gas jet involve three distinct and sequential stages (as recalled in the Introduction): aerodynamic break-up of the injected suspension stream into smaller droplets, evaporation of the solvent and release of individual particles or agglomerates in the gas jet, melting of the agglomerates [7-11,17]. Very small agglomerates or small non-agglomerated primary particles will be easily melted but they will also get significantly slower and colder before impacting onto the substrate; very large ones, by contrast, will be difficult to melt.

More specifically, when suspensions are produced using nanometric primary particles, agglomerates are typically formed $[7,8,10,33]$, so that the in-flight behaviour depends on the agglomerate size. Micrometric particles, by contrast, could be released as individual particles $[7,8,10]$.

Various suspension properties therefore affect the spraying process, including viscosity, surface tension, agglomeration behaviour (agglomerate size and agglomerate strength), etc. The suspensions employed in the present study, however, have very similar viscosity, so that they all exhibit comparable flow characteristics inside the feeding hose and the injection nozzle during the HVSFS process. These suspensions also possess analogous surface tension, as they feature identical liquid phase composition, identical solid content and same $\mathrm{pH}$; consequently, the fragmentation behaviour of the suspension stream injected inside the HVOF gas jet, which depends on its viscosity and surface tension (as shown by various authors [9-11]) will also be analogous.

The differences between the coatings have therefore no significant influence from feeding-related factors and depend mainly on the size of the primary powder particles and of the agglomerates formed in the suspensions. The agglomeration behaviour of the two nanopowders, in particular, is deeply affected by their diverse surface chemistries, which are reflected by their very different native $\mathrm{pH}$ values (Section 3.1): this is indeed the only relevant difference occurring between two powders having analogous primary particle size and shape (Figs. 1, 2, Table 2). The chemical composition of all of the powders is also analogous, so that it cannot have any significant influence on the coating properties.

\subsection{Deposition mechanisms with micron-sized powders (CT suspension)}

As noted in Sections 3.2.1 and 3.2.2, both CT coatings consist of a homogeneous distribution of well-flattened lamellae, with diameters from $\leq 1 \mu \mathrm{m}$ to $\sim 6 \mu \mathrm{m}$ (Figs. $6 \mathrm{~A}$ and $11 \mathrm{~A}, \mathrm{~B}$ ): accordingly, a denselypacked stacking of lamellae is achieved, which explains the low porosity and small average pore size (Table 3), the low surface roughness (Table 4) and the high cohesive strength (high hardness and elastic modulus, Figs. 12,13) of these coatings. Although these HVSFS-deposited lamellae are smaller than conventionally-sprayed ones (which typically have diameters of $>20 \mu \mathrm{m}$ ), the crystalline grain structure of most of them, characterised by columnar grains of $\sim 100 \mathrm{~nm}$ width (Fig. 6B), is definitely comparable to conventional HVOF-sprayed $\mathrm{Al}_{2} \mathrm{O}_{3}$ [27].

The size of the molten droplets originating these lamellae can be computed if an estimated value of the lamella flattening ratio is assumed. The flattening ratio of suspension plasma-sprayed lamellae is generally believed to be about 2 [7,11], i.e. much lower than that of conventional plasma-sprayed lamellae (which is about 4-5), because suspension plasma-sprayed molten agglomerates possess lower momentum than conventionally-sprayed powder particles: not only is their mass lower, but their low inertia also results in low impact velocity. In the present case, however, these lamellae seem quite well flattened, so that the average flattening ratio is presumably higher than 2. As an example, the lamella indicated by an arrow in Fig. 6A could be considered: its diameter is $\sim 5.9 \mu \mathrm{m}$ and its thickness is $\sim 0.7 \mu \mathrm{m}$, so that the radius of a spherical molten droplet of equivalent volume would be $\sim 1.66 \mu \mathrm{m}$. This means a flattening ratio of $\sim 3.55$. As this is one of the largest observable lamellae, the average flattening ratio can be conservatively assumed to be $\sim 3$. This means the lamellae 
Table 3

Porosity, average pore size, thickness, deposition efficiency and $\alpha-\mathrm{Al}_{2} \mathrm{O}_{3} / \gamma-\mathrm{Al}_{2} \mathrm{O}_{3}$ phase ratio of the HVSFS-deposited coatings.

\begin{tabular}{|c|c|c|c|c|c|}
\hline Coating & Porosity $^{\mathrm{a}}(\%)$ & Average pore size $(\mu \mathrm{m})$ & Thickness $(\mu \mathrm{m})$ & Deposition efficiency (\%) & $\alpha-\mathrm{Al}_{2} \mathrm{O}_{3} / \gamma-\mathrm{Al}_{2} \mathrm{O}_{3}$ ratio (\%) \\
\hline CT-1 & $2.43 \pm 0.16$ & $0.48 \pm 0.04$ & $66.8 \pm 2.7$ & 39 & 19.5 \\
\hline CT-2 & $2.15 \pm 0.33$ & $0.42 \pm 0.04$ & $109.2 \pm 2.6$ & 58 & 15.4 \\
\hline NA-1 & $4.69 \pm 0.37$ & $0.63 \pm 0.03$ & $81.8 \pm 2.1$ & 45 & 18.6 \\
\hline NA-2 & $3.95 \pm 0.65$ & $0.60 \pm 0.05$ & $85.4 \pm 4.6$ & 47 & 11.1 \\
\hline TAI-1 & $7.38 \pm 1.51$ & $1.02 \pm 0.16$ & $33.1 \pm 1.8$ & 13 & 23.1 \\
\hline TAI-2 & $6.83 \pm 1.50$ & 0.990 .18 & $34.7 \pm 2.2$ & 19 & 19.7 \\
\hline $\mathrm{CT}+\mathrm{NA}-1$ & $5.29 \pm 0.46$ & $0.67 \pm 0.04$ & $121.4 \pm 3.3$ & 70 & 15.2 \\
\hline $\mathrm{CT}+\mathrm{NA}-2$ & $4.63 \pm 0.59$ & $0.67 \pm 0.07$ & $121.2 \pm 3.9$ & 70 & 12.2 \\
\hline $\mathrm{CT}+\mathrm{TAI}-1$ & $5.57 \pm 0.53$ & $0.64 \pm 0.05$ & $94.34 \pm 2.3$ & 52 & 17.9 \\
\hline $\mathrm{CT}+\mathrm{TAI}-2$ & $5.66 \pm 1.04$ & $0.65 \pm 0.07$ & $100.1 \pm 2.4$ & 55 & 9.8 \\
\hline $\mathrm{NA}+\mathrm{TAI}-1$ & $5.74 \pm 1.14$ & $0.77 \pm 0.14$ & $58.0 \pm 2.7$ & 32 & 19.7 \\
\hline $\mathrm{NA}+\mathrm{TAI}-2$ & $4.66 \pm 0.28$ & $0.63 \pm 0.07$ & $61.0 \pm 2.9$ & 34 & 13.8 \\
\hline $\mathrm{CT}+\mathrm{NA}+\mathrm{TAI}-1$ & $6.64 \pm 0.77$ & $0.85 \pm 0.17$ & $63.1 \pm 3.7$ & 35 & 24.6 \\
\hline $\mathrm{CT}+\mathrm{NA}+\mathrm{TAI}-2$ & $3.60 \pm 0.37$ & $0.53 \pm 0.03$ & $80.2 \pm 3.3$ & 44 & 16.4 \\
\hline
\end{tabular}

a The porosity and average pore size were measured by image analysis on 5 SEM micrographs taken at random locations on the cross-sections of the coatings.

b Computed using Eq. (1).

found in the present coating are produced by molten droplets whose diameter is typically $\leq 2 \mu \mathrm{m}$; it may be hypothesised that almost no individual particle or agglomerate exceeding a threshold diameter of about $2.5 \mu \mathrm{m}$ will give rise to a flattened lamella. This probably happens because they are too large to be entirely melted at the spraying conditions examined in this study.
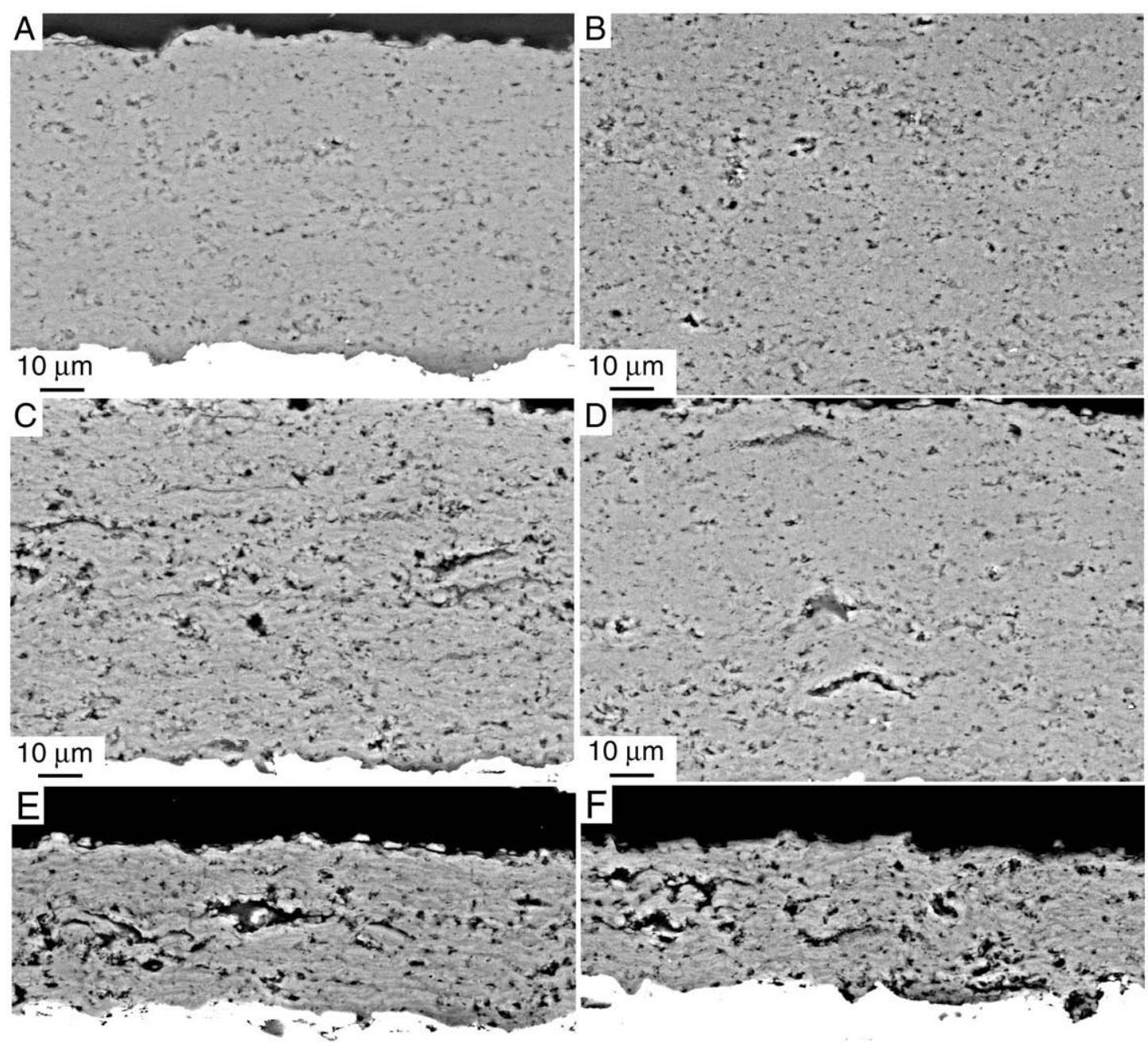

$10 \underline{\mu \mathrm{m}}$

$10 \mu \mathrm{m}$

Fig. 5. Cross-sectional SEM micrographs (backscattered electrons, 1000× magnification) of the CT-1 (A), CT-2 (B), NA-1 (C), NA-2 (D), TAI-1 (E), TAI-2 (F) coatings. 


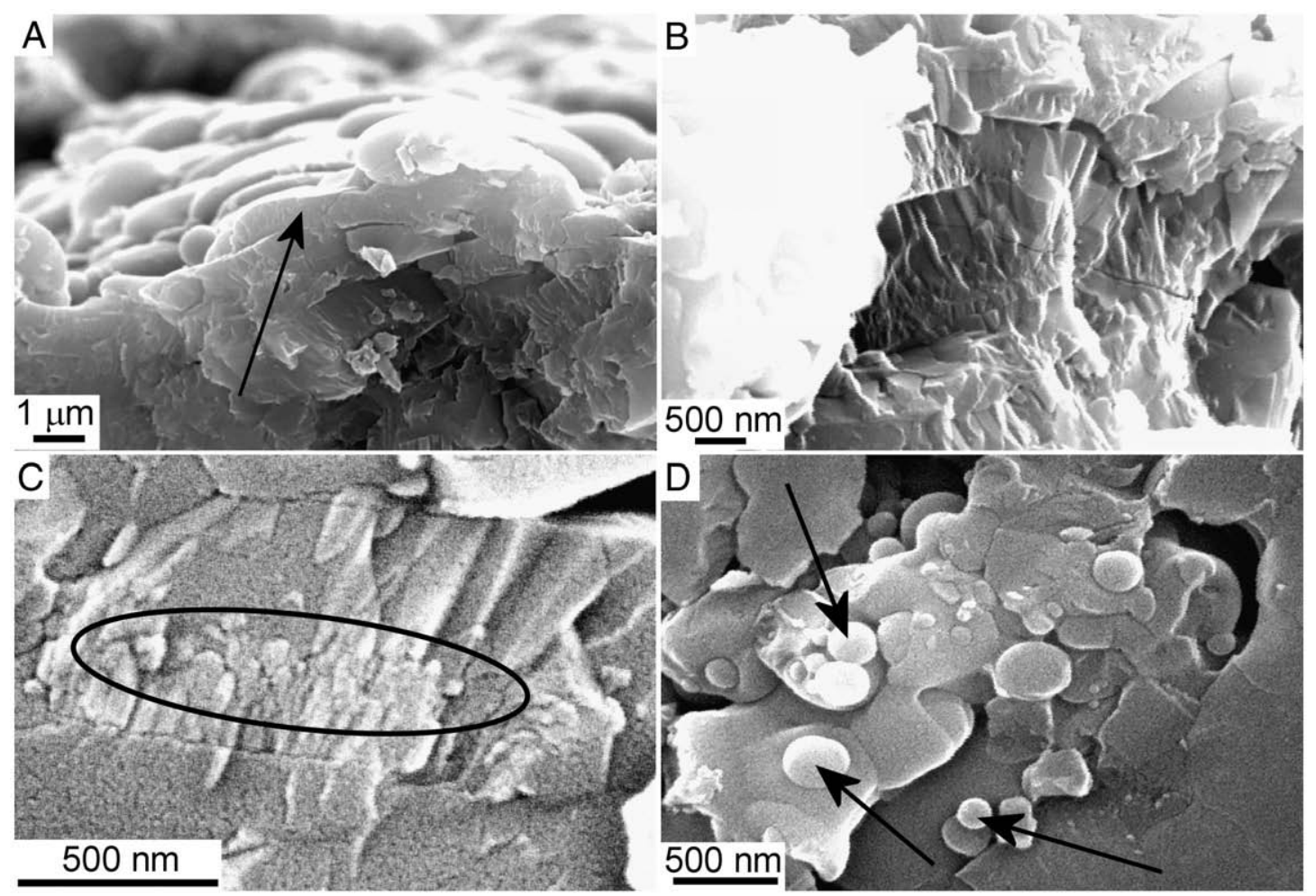

Fig. 6. SEM micrographs (secondary electrons) of the fractured section of the CT-2 coating: region close to the top surface (A); view of the columnar structures inside the lamellae (B); detail of very small equiaxed grains in the middle of a lamella (C, circle) and of small rounded particles (D, arrows) embedded in the coating.

It should be noted that, in conventional HVOF-spraying of ceramics using similar gas-fuelled torches with rear injection of dry powders, the particle size distribution of the feedstock (typically $5-15 \mu \mathrm{m}$

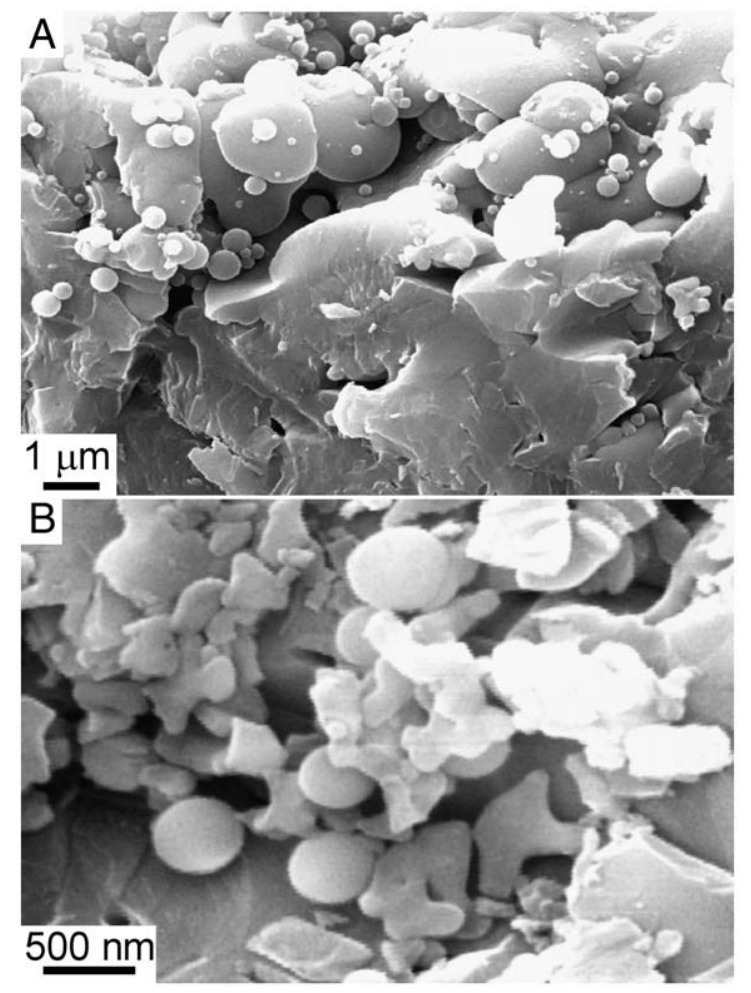

Fig. 7. SEM micrographs (secondary electrons) of the fractured section of the NA-2 coating: region close to the top surface $(A)$ and detail of an embedded nanoparticle cluster (B).
$[27,34])$ is larger than the above-mentioned threshold; nonetheless, a significant degree of particle melting can be achieved. Many factors can account for this difference between the HVOF and HVSFS processes:

- In suspension spraying, part of the thermal energy released by the combustion is employed for solvent evaporation, so that a lower amount of heat is available for melting the powder. In suspension plasma spraying, this issue is particularly relevant $[10,18]$; in the HVSFS process, the problem is lessened because the isopropanol burns after evaporation (as mentioned in Section 2.1 as well), thus releasing some additional thermal energy. Nonetheless, as the liquid phase of the present suspensions contains $60 \mathrm{wt} . \%$ water, the heat consumption for solvent evaporation is likely to have a significant impact on the process, so that no large agglomerate or particle can be fully melted.

- Finite element simulations also showed that, during the HVSFS process, the solvent evaporation stage can only be completed

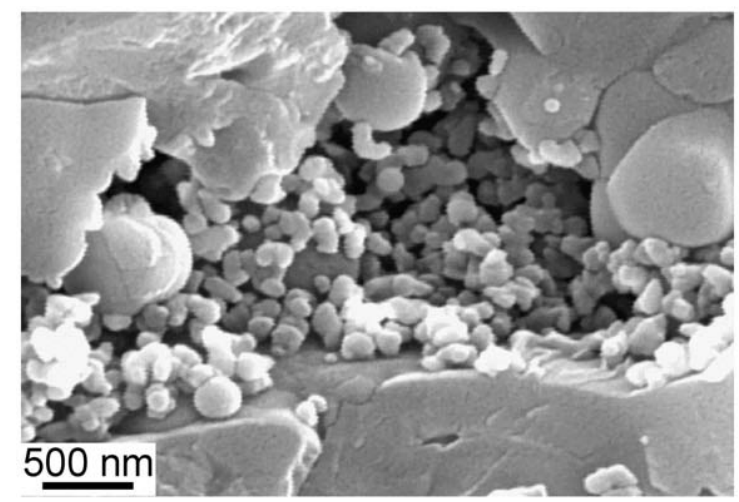

Fig. 8. SEM micrograph (secondary electrons) of the fractured section of the TAI-2 coating, which shows an embedded nanoparticle cluster. 


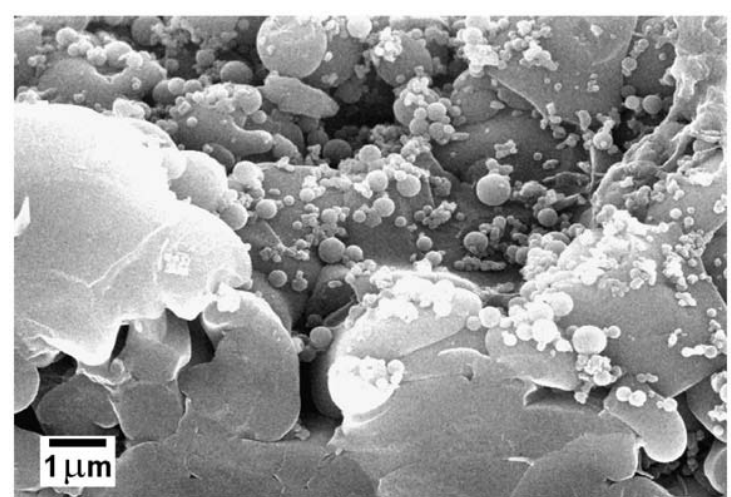

Fig. 9. SEM micrograph (secondary electrons) of the region close to the top surface on the fractured section of the $\mathrm{CT}+\mathrm{NA}+\mathrm{TAI}-2$ coating.

downstream of the combustion chamber, namely inside the expansion nozzle, where the combustion gases have already been somewhat cooled by the expansion up to sonic velocity [35].

- The inability of the process at melting the larger agglomerates or particles might also come from the peculiar combustion chamber geometry. Conventional gas-fuelled HVOF-spraying of refractory ceramics is typically carried out using cylindrical combustion chambers: they produce aerodynamic effects which prolong the residence time of the particles in the hottest section of the flame. Cylindrical combustion chambers, however, are unadvisable for the HVSFS process, because those aerodynamic effects cause the suspension to form deposits on the combustion chamber and nozzle walls: these deposits are a known source of defectiveness in the coatings, because some large drops of molten material may be detached from those deposits, from time to time, and be embedded in the coating (as shown by previous studies $[23,36]$ ). The conical combustion chamber (see Section 2) eliminates these aerodynamic effects [37] and prevents that problem, but it shortens the residence time of the particles or agglomerates in the combustion chamber itself. Moreover, a conical combustion chamber has smaller volume than a cylindrical one of identical length and base diameter, so that (at fixed gas flow rates) it produces higher gas pressure, resulting in larger gas stream velocity, which also reduces the residence time of the agglomerates in the gas jet, compared to conventional HVOF-
Table 4

Surface roughness parameters measured on the HVSFS-deposited coatings.

\begin{tabular}{llrllr}
\hline \multirow{2}{*}{ Coating } & \multicolumn{2}{l}{ Parameter set 1} & & \multicolumn{2}{l}{ Parameter set 2} \\
\cline { 2 - 3 } & $\mathrm{Ra}(\mu \mathrm{m})$ & \multicolumn{1}{c}{$\mathrm{Rz}(\mu \mathrm{m})$} & & $\mathrm{Ra}(\mu \mathrm{m})$ & \multicolumn{1}{l}{$\mathrm{Rz}(\mu \mathrm{m})$} \\
\hline CT & $1.31 \pm 0.03$ & $9.78 \pm 0.27$ & & $1.39 \pm 0.05$ & $9.88 \pm 0.74$ \\
NA & $1.84 \pm 0.05$ & $14.07 \pm 0.62$ & & $2.03 \pm 0.14$ & $16.51 \pm 1.99$ \\
$\mathrm{TAI}$ & $1.85 \pm 0.22$ & $17.88 \pm 5.42$ & & $2.52 \pm 0.25$ & $20.31 \pm 2.76$ \\
CT + NA & $1.82 \pm 0.08$ & $14.93 \pm 0.92$ & & $1.89 \pm 0.10$ & $16.04 \pm 1.14$ \\
CT + TAI & $1.63 \pm 0.06$ & $12.48 \pm 1.16$ & & $1.65 \pm 0.17$ & $13.39 \pm 1.88$ \\
CT + NA + TAI & $1.99 \pm 0.18$ & $15.87 \pm 1.54$ & & $2.45 \pm 0.18$ & $19.40 \pm 2.02$ \\
NA + TAI & $1.67 \pm 0.06$ & $13.90 \pm 1.36$ & & $1.95 \pm 0.09$ & $15.04 \pm 1.42$ \\
\hline
\end{tabular}

spraying. These factors hinder the complete melting of the largest agglomerates or particles. A faster gas jet, anyway, is desirable for the HVSFS process, as it may assist in preventing the particles from being significantly cooled and slowed down before impacting onto the substrate, a phenomenon affecting fine particles or fine agglomerates, which reproduce the gas jet velocity and temperature profiles [38]. This is consistent with the presently-observed lamellae showing higher flattening ratio than suspension plasma-sprayed ones.

A limited amount of partially unmelted large particles or agglomerates can be entrained in the coating; most of them, however, will rebound off the substrate. Based on the size distribution shown in Fig. 3A and in Table 2, if most of the particles and agglomerates of $\geq 2.5 \mu \mathrm{m}$ equivalent diameter are not deposited, almost $55 \%$ of the sprayed material is lost.

A second source of material loss during spraying can be the resolidification of the smallest particles. Fig. 6D (see arrows) consistently highlights some embedded spherical particles having a diameter of $\leq 500 \mathrm{~nm}$ : their spherical shape clearly reveals that they were fully melted in the gas jet, but had started to re-solidify before impacting onto the substrate. These particles have such low thermal and mechanical inertia that they become colder and slower at a certain distance from the nozzle exit [38], in spite of the previously-discussed high velocity of the gas stream and of the low stand-off distance. Whereas some of them could be embedded in the coating, it can be expected that others will not be deposited. The material loss because of re-solidified small particles, however, is not as significant as that caused by unmelted large particles and agglomerates; indeed, according to the cumulative curve in Fig. 3A,

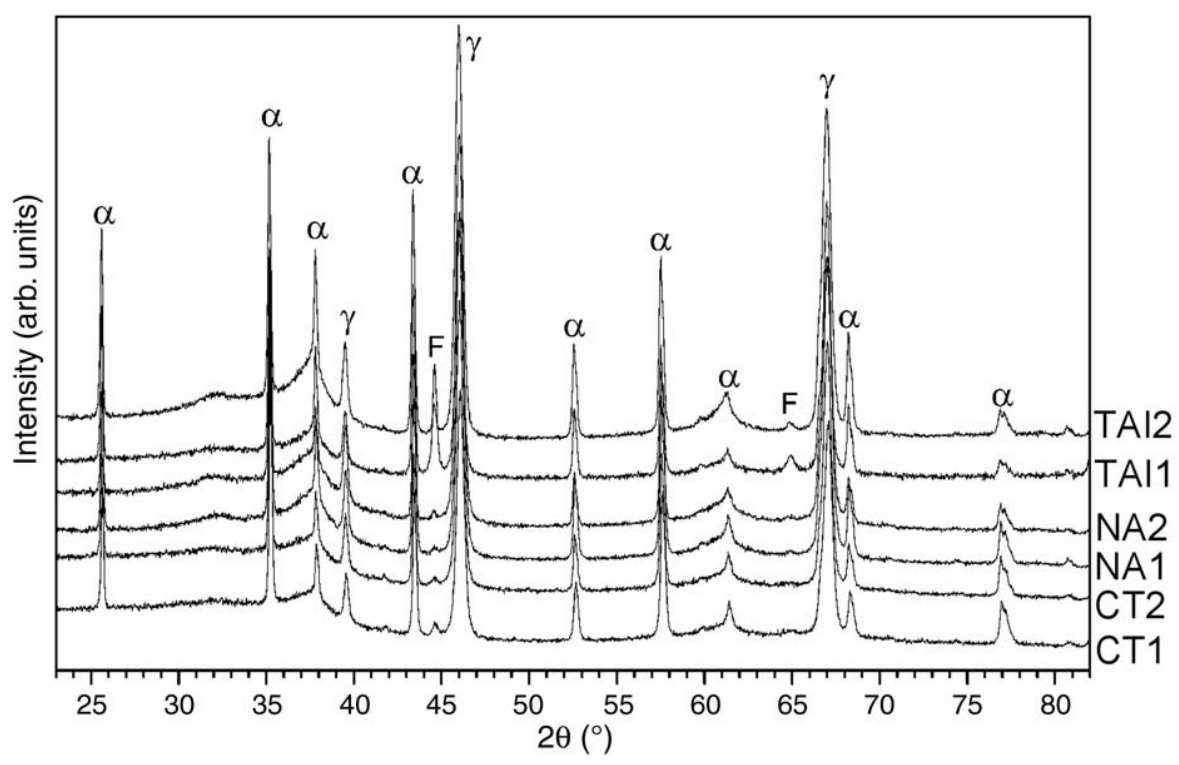

Fig. 10. XRD patterns of the CT-1, CT-2, NA-1, NA-2, TAI- 1 and TAI-2 coatings. Legend: $\alpha=\alpha-\mathrm{Al}_{2} \mathrm{O}_{3}$ (JCPDS 10-173); $\gamma=\gamma-\mathrm{Al}_{2} \mathrm{O}_{3}$ (JCPDS 10-425); F= ferrite (Fe-b.c.c., JCPDS 6-696). 

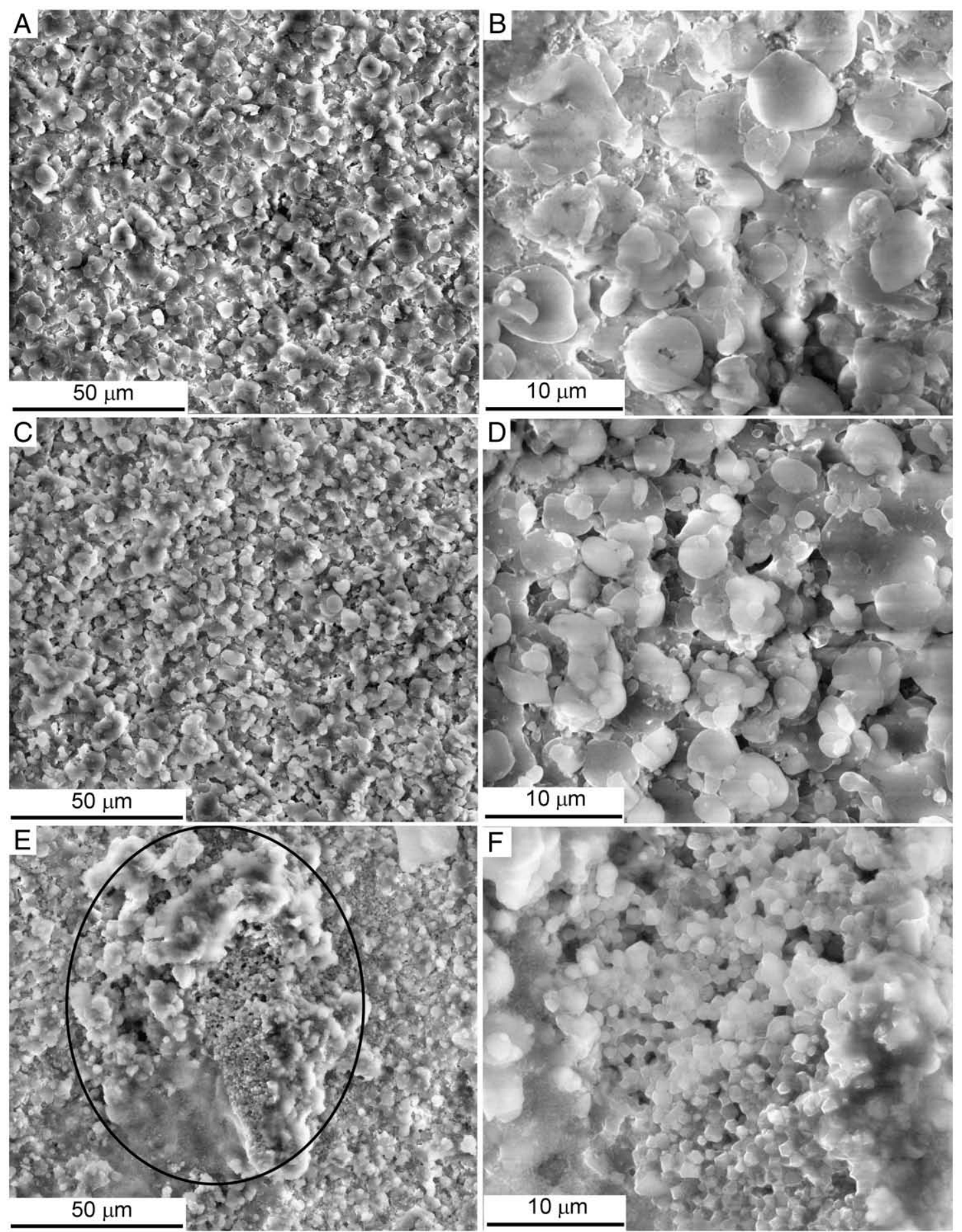

Fig. 11. ESEM micrographs (secondary electrons) of the surface morphology of the CT-1 (A,B), NA-1 (C,D) and TAI-1 (E,F) coatings. The circle in panel E indicates a large unmelted nanoparticle agglomerate; panel $\mathrm{F}$ shows a detail of the unmelted nanoparticles.

only $\sim 5 \%$ of the solid content of the suspension has a size of $\leq 500 \mathrm{~nm}$. Most of the very fine particles, indeed, are likely to enter into larger agglomerates, instead of remaining as individual particles.

The overall loss due to the largest ( $55 \%)$ and smallest $(\sim 5 \%)$ particles and agglomerates can account quite well for the measured deposition efficiency of 39\% (Table 3). This also means that the fraction of deposited particles and agglomerates in the $500 \mathrm{~nm}-2.5 \mu \mathrm{m}$ size range is very large. Considerably high deposition efficiencies could therefore be expected if the powder characteristics and suspension formulation could be tailored in order to produce a size distribution entirely comprised in this optimal range.
The deposition efficiency of the CT-2 coating is larger: this could be produced by the disruption of some large agglomerates into smaller ones and/or into primary particles under the spray parameter set \#2. Based on the previous considerations, indeed, the large agglomerates account for most of the material loss during spraying; therefore, such significant variation in deposition efficiency (from 39\% to 58\%) can only be explained by a considerable reduction in the loss of those agglomerates. The analyses of the curves in Figs. $3 \mathrm{~A}$ and $2 \mathrm{~A}$ and of the data in Table 2 suggest that, while $\sim 40 \%$ of the material having a size $\geq 2.5 \mu \mathrm{m}$ is made up of large nonagglomerated primary particles, $\sim 60 \%$ consists of large agglomerates of 

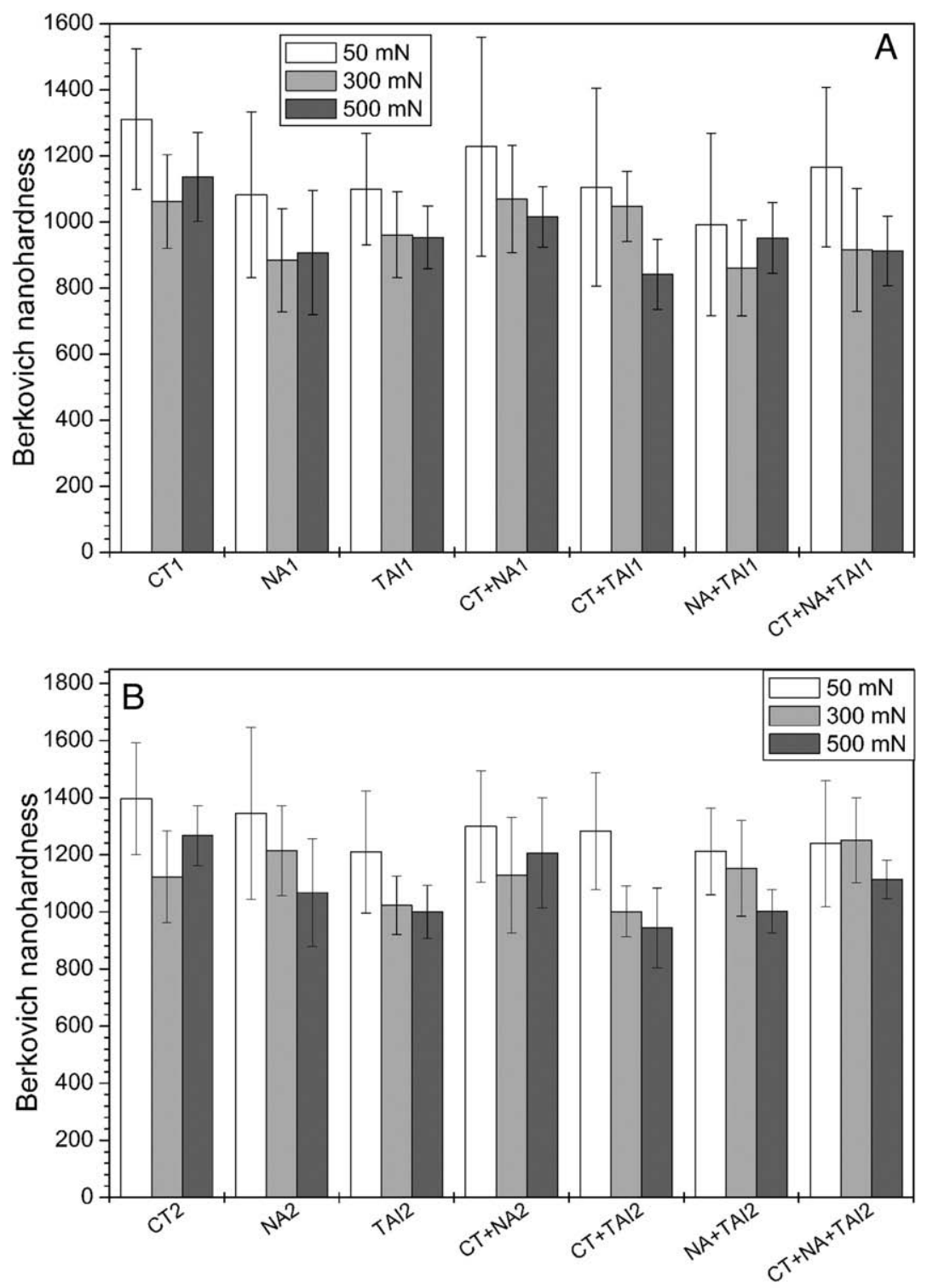

Fig. 12. Berkovich nanohardness of the coatings sprayed using the parameter set 1 (A) and 2 (B).

smaller primary particles. If all of those agglomerates would be disrupted into particles or agglomerates whose size allows melting and deposition, the increase in overall deposition efficiency would be of about 33\%. The actual improvement is obviously lower.

Disruption could occur after the solvent evaporation, because of turbulence in the gas jet, as suggested in Ref. [7], and it is made possible by the relatively weak cohesive strength of the agglomerates themselves (see Section 3.1). Accordingly, the gas jet turbulence is certainly enhanced by adopting larger fuel and oxygen flow rates (as it occurs when the spray parameter set \#2 is employed, see Table 1), as they cause a substantial increase in the flow rate of exhaust gases.

\subsection{Deposition mechanisms with nano-sized powders (NA and TAI suspensions)}

Differently from the CT powder, which is only partly agglomerated in the suspension, the NA one is entirely agglomerated (Fig. 3B and Table 2), so that the lamella size in the coating depends on the agglomerate size, rather than on the primary (nanometric) particle size.

Compared to the particle + agglomerate size distribution found in the CT suspension, the agglomerates in the NA suspension generate a finer size distribution (compare Fig. 3A and B). Consequently, the lamellae in the NA coatings are smaller and have a broader size distribution than in the CT ones (compare Fig. 7A to Fig. 6A and Fig. 11C,D to Fig. $11 \mathrm{~A}, \mathrm{~B}$ ): most of them are $2-3 \mu \mathrm{m}$ wide, consistently with the $\sim 1 \mu \mathrm{m}$ distributive curve peak. Moreover, the small rounded particles $(\sim 200-500 \mathrm{~nm}$ diameter $)$ in the NA coating are more numerous than those in the CT one: accordingly, the amount of agglomerates having a size of $\leq 500 \mathrm{~nm}$ is $\sim 8 \%$ in the NA suspension and $\sim 5 \%$ in the CT one (Fig. 3A,B).

The higher defectiveness, larger surface roughness and lower mechanical strength (lower hardness and elastic modulus, Figs. 12, 13) of the NA coatings, compared to the CT ones, can therefore be accounted for both by the larger abundance of small droplets $(\leq 500 \mathrm{~nm})$, which were presumably partly re-solidified before impact, and by the lower average momentum of molten droplets at impact (in accordance to the smaller average lamella size), which results in a less efficient packing of the lamellae.

Nonetheless, the lower amount of large agglomerates in the NA suspension as compared to the CT suspension (agglomerates exceeding an equivalent diameter of $2.5 \mu \mathrm{m}$ constitute only $35 \%$ of the overall agglomerate distribution in the NA suspension) results in higher deposition efficiency under the spray parameter set \#1 (Table 3). As 

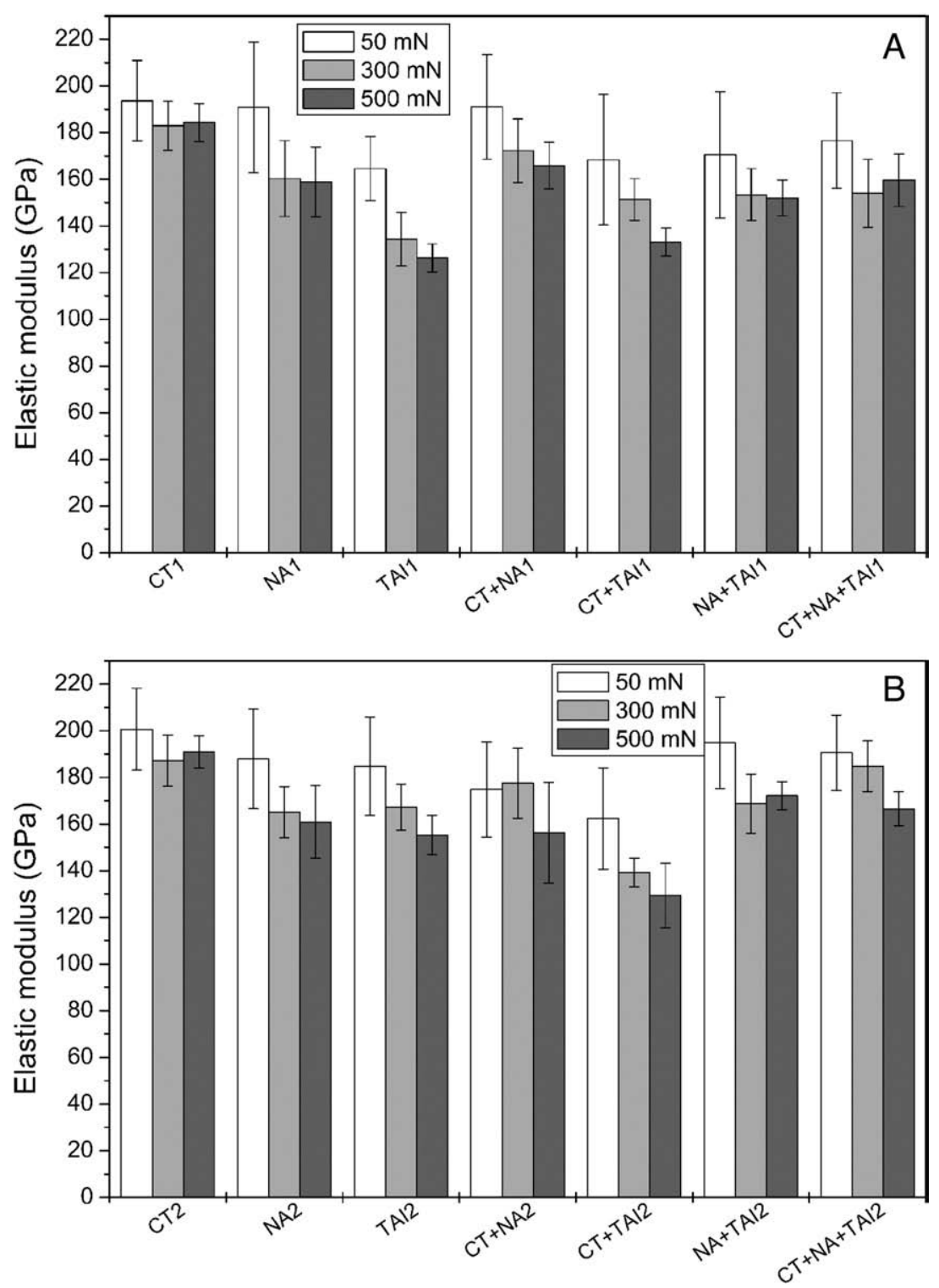

Fig. 13. Elastic moduli of the coatings sprayed using the parameter set 1 (A) and 2 (B).

mentioned previously, indeed, most of the material loss during spraying of the CT suspension was caused by the excessively large particles and agglomerates, rather than by the very fine ones.

The large nanoparticle agglomerates found in the NA suspension also behave much differently from the large micron-sized particle agglomerates present in the $\mathrm{CT}$ one. First of all, the former agglomerates possess larger cohesive strength, so that they are not disrupted by the increased gas jet turbulence under spraying conditions \#2. The increase in deposition efficiency from the NA-1 to the NA-2 coating is therefore not as remarkable as that from the CT- 1 to the CT- 2 coating. Secondly, the NA agglomerates consist of an extremely large number of nanoparticles, whereas the $\mathrm{CT}$ agglomerates consist of few micrometric particles. Most of the largest CT agglomerates, therefore, probably remain entirely unmelted and rebound upon high velocity impact (as previously mentioned in Section 4.1). By contrast, the outer rim of the largest NA agglomerates can easily be melted, whereas the core remains unmelted: a non-negligible amount of such agglomerates can become embedded in the coating (which also accounts for the larger thickness of the NA-1 coating, compared to the CT-1 one), producing localised weak spots (Fig. 7B). Although these agglomerates possess sufficient cohesion (while inside the suspension) in order not to be entirely dispersed by the ultrasonication treatment (see Section 3.1), their mechanical strength is obviously extremely poor; indeed, the individual nanoparticles are only held together by surface interactions. Consequently, during polishing, the nanoparticles can be pulled out, giving rise to those large, elongated defects, which provide the third contribution to the higher overall porosity of the NA coatings in comparison to the CT ones (see Section 3.2.1 and Fig. 5C,D). An analogous pull-out phenomenon was previously reported by the authors for some HVSFS-deposited $\mathrm{TiO}_{2}$ coatings obtained from nanoparticle suspensions $[21,39]$. As noted in those references, the occurrence of such pull-outs might indicate the porosity values measured by image analysis on the polished crosssections might be slightly overestimated. Nonetheless, as the mechanical strength of these unmelted regions is definitely insufficient for providing a meaningful contribution to the support of any external load, they do act, from a mechanical point of view, almost as if they were pores. The presence of such unmelted agglomerates and of the resulting elongated pull-out defects on the polished cross-sections is therefore, at any rate, an undesirable flaw for any mechanical application.

The TAI suspension contains much larger agglomerates than the NA one: only 25\% of the agglomerates are smaller than $2.5 \mu \mathrm{m}$. As explained in Section 3.1, indeed, in spite of the similarity between the 
size, morphology and composition of the primary particles, the TAI powder possesses a different surface chemistry. Accordingly, the coatings are much thinner than the CT and NA ones and their deposition efficiency is $<20 \%$; furthermore, they contain many more elongated defects due to the embedment of a larger amount of those partly unmelted nanoparticle agglomerates (Fig. 8). This also explains the higher $\alpha-\mathrm{Al}_{2} \mathrm{O}_{3}$ content of the TAI- 1 and TAI- 2 coatings. The cohesiveness of such agglomerates also accounts for the limited sensitivity of the coating thickness to changes in the deposition parameters, as for the NA coating, as well.

\subsection{Deposition mechanisms with mixed-powder suspensions}

The tendency of the TAI powder toward agglomeration also affects the mixed-powder suspensions (CG + TAI, CG + NA + TAI, NA + TAI); indeed, all of their distributive curves exhibit a multimodal behaviour with a peak at about $10 \mu \mathrm{m}$ (Section 3.1, Fig. 3E-G), which indicates that many agglomerates are too large to be entirely melted. This behaviour has obvious unfavourable consequences on the microstructure, thus explaining the generally higher porosity and lower mechanical properties, compared to the pure NA and CT coatings (Table 3, Figs. 12, 13). Consistently, on the top surface of the CT + NA + TAI coatings, lots of small rounded droplets (re-solidified small agglomerates) and of unmelted nanoparticles (due to the impact of large unmelted agglomerates) were noted (Fig. 9) and clusters of unmelted nanoparticles also appeared on the cross-section, similarly to those of the pure TAI coating, shown in Fig. 8.

It was observed, however, that the CT + NA mixture produces an interesting synergistic effect on the deposition efficiency (Section 3.2.1 and Table 3). The agglomerate size distribution found in the CT + NA suspension (Fig. 3D) features two maxima located at about $1 \mu \mathrm{m}$ and $4.5 \mu \mathrm{m}$, respectively. It can be argued that the first maximum is contributed by some non-agglomerated CT particles and by some NA particle agglomerates (compare to Fig. $3 \mathrm{~A}$ and $\mathrm{B}$ ), whereas the second maximum could be given by mixed agglomerates of CT and NA particles: small NA particles surround one or few large CT particles in a single agglomerate. In such agglomerate, the outer shell of nanoparticles can be entirely melted, while the large particle in the core remains mostly unmelted. Such agglomerate can stick to the surrounding material and be embedded in the coating, enhancing the deposition efficiency. In this case, therefore, the above-mentioned threshold of $2.5 \mu \mathrm{m}$ is exceeded because of the peculiar nature of the agglomerate itself. These agglomerates cannot, however, spread and give rise to well-flattened lamellae, so that the porosity of the CT + NA coatings is higher than that of the pure CT coatings (Table 3 ).

This phenomenon might also be taking place in the CT + TAI coating, because the deposition efficiency and thickness of the CT + TAI- 1 and CT + TAI- 2 coatings are somewhat larger than those of the CT-1 alone. This phenomenon is, however, less effective, as these two coatings exhibit lower thickness and deposition efficiency than the CT-2, the CT + NA-1 and the CT + NA-2 ones; indeed, the agglomerates are way too large (see the agglomerate size distribution in Fig. 3E), on account of the above-mentioned unfavourable cohesive tendency of the TAI particles.

\subsection{Effects of the deposition parameters}

Changing the deposition parameters from set \#1 to set \#2 seems to produce some common effects on the properties of the coatings, regardless of the suspension employed. Specifically, the $\alpha-\mathrm{Al}_{2} \mathrm{O}_{3} / \gamma-\mathrm{Al}_{2} \mathrm{O}_{3}$ phase ratio always decreases (Table 3 ) and the mechanical properties (particularly the hardness) increase: in particular, Fig. 14 shows the increase in the $500 \mathrm{mN}$-nanohardness values, when changing from parameter set \#1 to set \#2, but an analogous behaviour also occurs for the hardness values measured at 50 and $300 \mathrm{mN}$. None of these phenomena, however, is particularly remarkable; indeed, the dominant role in determining the characteristics of the coatings is played by the nature of the powder, as highlighted in Sections 4.1-4.3.

The $\alpha$-phase in conventional thermally-sprayed $\mathrm{Al}_{2} \mathrm{O}_{3}$ coatings comes from the direct embedment of unmelted material or grows inside the liquid phase in partly unmelted particles, where the surface of unmelted $\alpha-\mathrm{Al}_{2} \mathrm{O}_{3}$ acts as nucleus [40]. Either way, the $\alpha$-phase is related to the retention of unmelted material in the sprayed coatings. This consideration also holds for HVSFS-deposited coatings, as the comparison between the present results and some previous literature reports on suspension-sprayed alumina seems to suggest. Toma et al., indeed, employed a similar HVOF-suspension spraying process and obtained coatings with $>60 \% \alpha-\mathrm{Al}_{2} \mathrm{O}_{3}$ by using water-based suspensions (without organic solvents) [41], which obviously made the flame much colder than the present one, thus preventing extensive melting of the feedstock. On the other hand, coatings where the $\alpha$ $\mathrm{Al}_{2} \mathrm{O}_{3} / \gamma-\mathrm{Al}_{2} \mathrm{O}_{3}$ phase ratio was only about $3 \%$ were HVSFS-deposited by the authors using a suspension whose liquid phase contained $90 \mathrm{wt} . \%$ isopropanol [23]: compared to the present deposition conditions, this larger amount of organic solvent significantly enhanced the flame heat (as explained in Sections 2.1 and 4.2), so that it probably contained a larger fraction of molten droplets. It should be remarked that the spraying conditions in [23] were eventually unsuitable for practical applications, as the excessively large heat input, together with a different combustion chamber geometry, had resulted in the formation of deposits on the walls of the combustion chamber and of the expansion nozzle, which caused unacceptable "bumps" in the coating.

Accordingly, when using the CT suspension, the largest variation occurring from deposition parameter set \#1 to set \#2 (as widely discussed in Section 4.1) is the reduction in the amount of large and fully unmelted agglomerates in the gas jet, which obviously reduces the embedment of unmelted material in the resulting coating, as well. As only a small fraction of those agglomerates is embedded in the coating (many of them rebound, as noted previously), however, the change in phase composition of the CT coatings is definitely not as significant as the increase in their deposition efficiency (Table 3).

In the NA and TAI coatings, where the largest nanoparticle agglomerates probably have a melted rim and an unmelted core

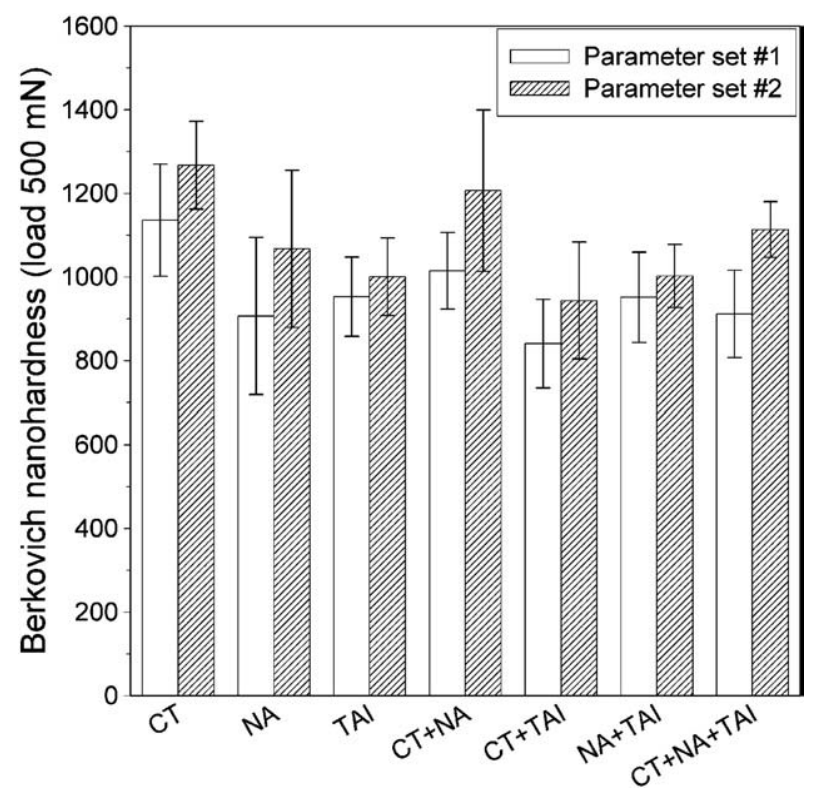

Fig. 14. Comparison between the Berkovich nanohardness values of the coatings obtained by spraying each suspension with parameter sets \#1 and \#2 (indentation load: $500 \mathrm{mN}$ ). 
(Section 4.2), the change in phase composition might be due to a slightly better melting of the outer rim of nanoparticles under parameter set \#2. Although most nanoparticle agglomerates do not disrupt (as previously noted), very few might have disrupted under spraying conditions \#2, giving a small additional contribution. Analogous considerations hold for the mixed-powder suspensions.

Whether some additional contribution to the $\alpha-\mathrm{Al}_{2} \mathrm{O}_{3}$ content could come from the small $(<500 \mathrm{~nm})$ embedded re-solidified particles might be debatable. On the one hand, in-flight resolidification is a slower process than impact quenching of molten lamellae and it may eventually allow the formation of the rhombohedral structure, as also suggested in [42]. On the other hand, ref. [40] indicates that, during spheroidisation of $\mathrm{Al}_{2} \mathrm{O}_{3}$ particles, the $\alpha$-phase is found only for particle diameters larger than $\sim 15 \mu \mathrm{m}$. If the small resolidified particles actually contribute to the $\alpha-\mathrm{Al}_{2} \mathrm{O}_{3}$ content, the ability of the hotter and faster gas jet obtained under spraying conditions \#2 at reducing in-flight re-solidification might give a further contribution to the decreased $\alpha$-phase amount, particularly for the coatings obtained from the NA and TAI suspensions, where the presence of small $(<500 \mathrm{~nm})$ agglomerates is more significant.

All of these phenomena (better melting of the agglomerate rims, agglomerate disruption, reduced in-flight re-solidification of small particles), however, can only give small contributions; accordingly, the phase composition change of the nanopowder and mixed-powder coatings is never so significant.

The reduced embedment of unmelted and re-solidified material also accounts for the slight improvement in the hardness values. Moreover, the increased system temperature during deposition (Table 1) might produce a better interlamellar cohesion by giving individual lamellae some more time in order to spread and adhere strongly to one another [43]. Once again, as none of the abovedescribed phenomena is particularly remarkable, the hardness changes are quite small.

\subsection{General remarks}

Some additional very important features must be underlined. First of all, the thickness deposited per torch cycle is, in all cases, very remarkable, if compared to literature values for suspension plasmasprayed coatings, as already noted in Section 3.2.1. Some of the deposition efficiency values are in excess of 50\% (being even as large as $70 \%$ when using the CT + NA suspension), which means they are comparable or superior to those observed during conventional HVOFspraying of $\mathrm{Al}_{2} \mathrm{O}_{3}$ [44]. The ability of the HVSFS process in producing remarkable deposition efficiencies is certainly favoured by the axial injection system. As previously reported in other papers, indeed, the axial injection of the powder inside the combustion chamber of the torch constitutes an advantage (at least, when dense coatings must be produced) over the radial injection system adopted in the conventional DC plasma torches which have been employed for most suspension plasma spraying experiments. Axial injection, indeed, ensures that most suspension droplets will be in contact with the hottest section of the gas jet $[21,23]$. Using radial injection systems, by contrast, a certain amount of droplets can be dragged by the plasma jet fringes: the solid phase contained in them remains largely unmelted $[13,45]$.

Secondly, these coatings are also much smoother than conventional thermally-sprayed ones: even when the finest commerciallyavailable dry powder feedstock is used, the average roughness ( Ra) of conventionally-sprayed coatings is $2.5-3.5 \mu \mathrm{m}[46,47]$, i.e. about twice as much as the CT coatings obtained in the present research. This result is of the utmost importance, as surface finishing (grinding/ polishing) of hard thermally-sprayed coatings is often a slow and expensive process, which largely increases the overall cost of a coated component. A lot of attention has accordingly been recently devoted to the near-net-shape manufacturing of smooth thermally-sprayed coatings [46-48] or to the development of faster and automated surface finishing techniques [49]; however, the above-mentioned papers never reported such low roughness values as the ones presently obtained.

A final note concerns the indentation size effect found in the nanoindentation tests: the measured values of hardness and elastic modulus decrease with increasing normal load (Figs. 12, 13). Such effect has already been quite well documented for thermally-sprayed coatings $[23,27,50]$ : it is known to be related to a different response of the coatings when tested over different length scales, on account of their lamellar nature [51]. As the load increases, a larger material volume is affected by the indentation, so that the interlamellar cohesion (the weakest link in every thermally-sprayed coating) plays a more important role on the mechanical response and the probability of finding a large defect in this volume increases; consequently, the measured values decrease.

In conventional thermally-sprayed coatings, where lamellae are larger, low-load indentation marks involve only one or few lamellae, so that the material response is largely influenced by the intralamellar mechanical properties [27]. If this assumption were true for the presently-considered HVSFS coatings, the hardness and elastic modulus values of the various coatings measured at $50 \mathrm{mN}$ should be quite similar (as the intralamellar properties should be substantially similar in all coatings) and the largest differences should only emerge at the larger indentation loads ( $300 \mathrm{mN}$ and $500 \mathrm{mN}$ ). By contrast, quite significant differences appear at the $50 \mathrm{mN}$ indentation load, as well: because of the small lamella size (as previously discussed in Sections 3.2.2 and 3.2.3, the largest lamellae have a diameter of about $6 \mu \mathrm{m}$ ), even the smaller indentation load probes several lamellae, so that both the intralamellar material properties and the interlamellar cohesion contribute to the overall response. Obviously, as the load increases, the probed volume increases and the measured properties decrease, on account of the same reasons discussed above.

\section{Conclusions}

The properties of HVSFS-deposited coatings are deeply affected by the characteristics of the powder feedstock chosen for the suspension preparation, particularly by its primary particle size and by its agglomeration behaviour (agglomerate size and agglomerate strength).

Smooth $(\operatorname{Ra} \sim 1.3 \mu \mathrm{m})$, dense and hard coatings are obtained when the suspension contains individual particles or agglomerates of 1-2 $\mu$ m diameter, which become fully melted during spraying and impact onto the substrate with high momentum; indeed, they produce a uniform distribution of fine, well-flattened lamellae (flattening ratio of 3-3.5) having homogeneous size. It is interesting to note that a very recent numerical study [52] seems to suggest that the optimal diameter of $\mathrm{Al}_{2} \mathrm{O}_{3}$ particles and/or agglomerates for axial injection-suspension plasma spraying is also $\sim 1.5 \mu \mathrm{m}$; indeed, the finite element simulation of the axial injection-suspension plasma spraying process performed in [52] showed that, at the proper spray distance, particles or agglomerates of this size can impact at high velocity in a fully melted condition.

Excessively small particles and agglomerates $(<500 \mathrm{~nm})$ do not flatten so effectively, both because they attain lower momentum and because they may re-solidify before impact, on account of their low inertia. Large particles and agglomerates $(>2.5 \mu \mathrm{m})$, by contrast, remain partly or entirely unmelted.

Micron-sized powders (1-2 $\mu \mathrm{m})$ seem therefore highly-suited to the HVSFS process. Only a limited amount of agglomerates is formed in the suspension, and such agglomerates are sufficiently weak to be disrupted during spraying, when the flow rates of the combustion gases are large enough to produce highly-turbulent conditions. This 
means the process parameters can be adjusted for optimal deposition efficiency, which can exceed $50 \%$.

Nanometric powders (possessing much larger specific surface area), by contrast, are entirely agglomerated in the suspension. The surface chemistry of the powder takes on a decisive role, because it controls the agglomeration phenomenon. If the agglomerate size is limited to a few microns, good deposition efficiencies can still be achieved and sufficiently dense coatings are obtained. Otherwise, if very large agglomerates are formed, the deposition efficiency is impaired and the coatings contain numerous defects. The embedment of defects, in particular, is caused by the different behaviour of nanoparticle agglomerates and of micron-sized particle agglomerates. A large agglomerate consisting of few micron-sized particles remains totally unmelted and rebounds off the substrate; one consisting of many nanoparticles, by contrast, can melt along its surface, whereas its core is unmelted. This latter kind of agglomerate can stick to the surrounding material, giving rise to a porous, poorly-bonded region.

Additionally, nanoparticle agglomerates cannot be disrupted by increasing the gas jet turbulence, because their cohesive strength is much larger than that of micrometric particle agglomerates; therefore, it is difficult to enhance the deposition efficiency by varying the spraying parameters.

It should be remarked that the formation of large unmelted agglomerates of nanoparticles is certainly undesirable when dense coatings (e.g. for wear resistance or electrical insulation applications) must be produced; however, when nanostructured functional coatings must be deposited and/or when the chemical and structural composition of a heat-sensitive powder must not undergo thermal alteration during spraying, the embedment of unmelted agglomerates should be sought for (up to a certain extent).

When micron- and nano-sized powders are mixed in a single suspension, the density and the mechanical properties of the resulting coating are generally impaired, in comparison to the coatings obtained using pure micrometric powders, because the presence of nanoparticles will give rise both to very small agglomerates, which produce non-flattened spherical inclusions, and to large agglomerates, which produce large embedded defects. Under suitable conditions, however, synergistic effects leading to improved deposition efficiency are achieved. One or few large micrometric particles can indeed be surrounded by nanoparticles: such particular type of agglomerate can stick to the surrounding material, because its outer nanoparticle shell can easily be melted. If a suitable nanopowder is employed (i.e. one without a strong agglomeration tendency), the deposition efficiency can be improved (reaching values of $~ 70 \%$ ), in comparison to the pure nanopowder or the pure micrometric powder, although the coating will not be as dense as those obtained using pure micrometric powder suspensions.

As a final note, future developments of the HVSFS apparatus could exploit the ability of the ultrasonication treatment at reducing the size of nanoparticle agglomerates in order to enhance the deposition efficiency and the coating density, particularly when spraying nanoparticle suspensions. Another possible way to prevent the formation of excessively large agglomerates could be the addition of proper dispersants to the suspensions.

\section{Acknowledgements}

Partly supported by PRRIITT (Regione Emilia-Romagna, Italy), netlab "INTERMECH", and by MIUR, Italian Ministry for University and Research (Funds: "Programmi per l'incentivazione del processo di internazionalizzazione del sistema universitario").

The authors are particularly grateful to Mr. Nico Stiegler, Mr. Andreas Vogel and Mr. Willi Schwan (IMTCCC) for the assistance in the experimental activities.

Many thanks to Ing. Elisabetta Parsini (Mineral S.r.l., Formigine (MO), Italy) for providing the CT-800 powder.

\section{References}

[1] R. Rampon, F.-L. Toma, G. Bertrand, C. Coddet, J. Therm. Spray Technol. 15 (2006) 682.

[2] C. Monterrubio-Badillo, H. Ageorges, T. Chartier, J.F. Coudert, P. Fauchais, Surf. Coat. Technol. 200 (2006) 3743.

[3] F.-L. Toma, G. Bertrand, D. Klein, C. Coddet, C. Meunier, J. Therm. Spray Technol. 15 (2006) 587.

[4] F.-L. Toma, G. Bertrand, S. Begin, C. Meunier, O. Barres, D. Klein, C. Coddet, Appl. Catal., B Environ. 68 (2006) 74.

[5] A. Killinger, M. Kuhn, R. Gadow, Surf. Coat. Technol. 201 (2006) 1922.

[6] X.Q. Ma, J. Roth, D.W. Gandy, G.J. Frederick, J. Therm. Spray Technol. 15 (2006) 670.

[7] H. Kaßner, R. Vaßen, D. Stöver, Surf. Coat. Technol. 202 (2008) 4355.

[8] C. Delbos, J. Fazilleau, V. Rat, J.F. Coudert, P. Fauchais, B. Pateyron, Plasma Chem. Plasma Process. 26 (2006) 393.

[9] J. Fazilleau, C. Delbos, V. Rat, J.F. Coudert, P. Fauchais, B. Pateyron, Plasma Chem. Plasma Process. 26 (2006) 371.

[10] P. Fauchais, R. Etchart-Salas, V. Rat, J.F. Coudert, N. Caron, K. Wittmann-Ténèze, J. Therm. Spray Technol. 17 (2008) 31.

[11] P. Fauchais, V. Rat, J.-F. Coudert, R. Etchart-Salas, G. Montavon, Surf. Coat. Technol. 202 (2008) 4309.

[12] F. Tarasi, M. Medraj, A. Dolatabadi, J. Oberste-Berghaus, C. Moreau, J. Therm. Spray Technol. 17 (2008) 685.

[13] O. Tingaud, A. Grimaud, A. Denoirjean, G. Montavon, V. Rat,J.F. Coudert, P. Fauchais, T. Chartier, J. Therm. Spray Technol. 17 (2008) 662.

[14] R. Rampon, C. Filiatre, G. Bertrand, J. Therm. Spray Technol. 17 (2008) 105.

[15] R. Gadow, A. Killinger, J. Rauch, Surf. Coat. Technol. 20 (2008) 4329.

[16] F.-L. Toma, L.-M. Berger, T. Naumann, S. Langner, Surf. Coat. Technol. 202 (2008) 4343.

[17] J. Oberste Berghaus, J.-G. Legoux, C. Moreau, F. Tarasi, T. Chráska, J. Therm. Spray Technol. 17 (2008) 91

[18] R. Rampon, O. Marchand, C. Filiatre, G. Bertrand, Surf. Coat. Technol. 202 (2008) 4337

[19] R. Tomaszek, L. Pawlowski, L. Gengembre, J. Laureyns, A. Le Maguer, Surf. Coat. Technol. 201 (2007) 7432.

[20] F.-L. Toma, G. Bertrand, S.O. Chwa, C. Meunier, D. Klein, C. Coddet, Surf. Coat Technol. 200 (2006) 5855.

[21] G. Bolelli, V. Cannillo, R. Gadow, A. Killinger, L. Lusvarghi, J. Rauch, Surf. Coat. Technol. 203 (2009) 1722.

[22] P. Fauchais, J. Phys., D, Appl. Phys. 37 (2004) R86.

[23] G. Bolelli, J. Rauch, V. Cannillo, A. Killinger, L. Lusvarghi, R. Gadow, J. Therm. Spray Technol. 18 (2009) 35.

[24] J.R. Davis, Handbook of Thermal Spray Technology, ASM International, Materials Park, OH, USA, 2004 175-213 pp.

[25] B.P. Singh, R. Menchavez, C. Takai, M. Fuji, M. Takahashi, J. Colloid Interface Sci. 291 (2005) 181.

[26] Y.-J. Shin, C.-C. Su, Y.-H. Shen, Mater. Res. Bull. 41 (2006) 1964

[27] G. Bolelli, L. Lusvarghi, T. Manfredini, F. Pighetti Mantini, R. Polini, E. Turunen, T. Varis, S.-P. Hannula, Int. J. Surf. Sci. Eng. 1 (2007) 38.

[28] Y.H. Dong, P. Scardi, J. Appl. Crystallogr. 33 (2000) 184.

[29] H.P. Klug, L.E. Alexander, X-Ray Diffraction Procedures for Polycrystalline and Amorphous Materials, John Wiley \& Sons, Inc., London, 1954 491-494 pp.

[30] H. Du, J.H. Shin, S.W. Lee, J. Therm. Spray Technol. 14 (2005) 453.

[31] W.C. Oliver, G.M. Pharr, J. Mater. Res. 7 (1992) 1564.

[32] R.J. Damani, D. Rubeša, R. Danzer, J. Eur. Ceram. Soc. 20 (2000) 1439.

[33] L. Pawlowski, Surf. Coat. Technol. 202 (2008) 4318.

[34] E. Turunen, T. Varis, S.-P. Hannula, A. Vaidya, A. Kulkarni,J. Gutleber, S. Sampath, H. Herman, Mater. Sci. Eng., A Struct. Mater.: Prop. Microstruct. Process. 415 (2006) 1.

[35] E. Dongmo, A. Killinger, M. Wenzelburger, R. Gadow, Surf. Coat. Technol. 203 (2009) 2139.

[36] G. Bolelli, J. Rauch, V. Cannillo, A. Killinger, L. Lusvarghi, R. Gadow, Mater. Lett. 62 (2008) 2772

[37] J. Rauch, N. Stiegler, A. Killinger, R. Gadow, in: B.R. Marple, M.M. Hyland, Y.-C. Lau, C.-J. Li, R.S. Lima, G. Montavon (Eds.), Thermal Spray 2009: Expanding Thermal Spray Performance to New Markets and Applications - Proceedings of the International Thermal Spray Conference, ASM International, Materials Park, OH, USA, 2009, p. 150

[38] E. Dongmo, M. Wenzelburger, R. Gadow, Surf. Coat. Technol. 202 (2008) 4470.

[39] G. Bolelli, V. Cannillo, L. Lusvarghi, R. Gadow, A. Killinger, J. Rauch, E. Bemporad, M. Sebastiani, in: B.R. Marple, M.M. Hyland, Y.-C. Lau, C.-J. Li, R.S. Lima, G. Montavon (Eds.), Thermal Spray 2009: Expanding Thermal Spray Performance to New Markets and Applications - Proceedings of the International Thermal Spray Conference, ASM International, Materials Park, OH, USA, 2009, p. 207.

[40] R. McPherson, J. Mater. Sci. 15 (1980) 3141.

[41] F.-L. Toma, L.-M. Berger, C.C. Stahr, T. Naumann, S. Langner, in: B.R. Marple, M.M. Hyland, Y.-C. Lau, C.-J. Li, R.S. Lima, G. Montavon (Eds.), Thermal Spray 2009: Expanding Thermal Spray Performance to New Markets and Applications - Proceedings of the International Thermal Spray Conference, ASM International, Materials Park, OH, USA, 2009, p. 168.

[42] F. Tarasi, M. Medraj, A. Dolatabadi, J. Oberste-Berghaus, C. Moreau, in: B.R. Marple, M.M. Hyland, Y.-C. Lau, C.-J. Li, R.S. Lima, G. Montavon (Eds.), Thermal Spray 2009: Expanding Thermal Spray Performance to New Markets and Applications Proceedings of the International Thermal Spray Conference, ASM International, Materials Park, OH, USA, 2009, p. 409.

[43] R. Dhiman, S. Chandra, Int. J. Heat Mass Transfer 48 (2005) 5625.

[44] V.V. Sobolev, J.M. Guilemany, J. Nutting, High Velocity Oxy-Fuel Spraying. Theory, Structure-Property Relationships and Applcations, Maney Publishing, London, UK, 2004 24-26 pp.

[45] R. Etchart-Salas, V. Rat, J.F. Coudert, P. Fauchais, N. Caron, K. Wittman, S. Alexandre, J. Therm. Spray Technol. 16 (2007) 857. 
[46] W. Tillmann, E. Vogli, I. Baumann, G. Matthaeus, T. Ostrowski, J. Therm. Spray Technol. 17 (2008) 924.

[47] T. Bause, F.-W. Bach, K. Möhwald, M. Erne, in: E. Lugscheider (Ed.), Thermal Spray 2008: Crossing Borders - Proceedings of the International Thermal Spray Conference, DVS Verlag, Düsseldorf, Germany, 2008, p. 64

[48] B. Wielage, A. Wank, H. Pokhmurska, T. Grund, C. Rupprecht, G. Reisel, E. Friesen, Surf. Coat. Technol. 201 (2006) 2032.
[49] M. Barletta, G. Rubino, G. Bolelli, L. Lusvarghi, J. Therm. Spray Technol. 17 (2008) 796

[50] S. Ghosh, S. Das, T.K. Bandyopadhyay, P.P. Bandyopadhyay, A.B. Chattopadhyay, J. Mater. Sci. 38 (2003) 1565.

[51] N. Margadant, J. Neuenschwander, S. Stauss, H. Kaps, A. Kulkarni, J. Matejicek, G. Rössler Surf. Coat. Technol. 200 (2006) 2805

[52] H.-B. Xiong, J.-Z. Lin, J. Therm. Spray Technol., in press, doi:10.1007/s11666-009-9349-7. 